\title{
On Hydrologic Similarity \\ 3. A Dimensionless Flood Frequency Model Using a Generalized Geomorphologic Unit Hydrograph and Partial Area Runoff Generation
}

\author{
Murugesu Sivapalan' and Eric F. WoOd \\ Water Resources Program, Department of Civil Engineering and Operations Research \\ Princeton University, Princeton, New Jersey
}

\author{
KEITH J. BeVEN
}

Institute of Environmental and Biological Sciences, University of Lancaster, Lancaster, England

\begin{abstract}
One of the shortcomings of the original theory of the geomorphologic unit hydrograph (GUH) is that it assumes that runoff is generated uniformly from the entire catchment area. It is now recognized that in many catchments much of the runoff during storm events is produced on partial areas which usually form on narrow bands along the stream network. A storm response model that includes runoff generation on partial areas by both Hortonian and Dunne mechanisms was recently developed by the authors. In this paper a methodology for integrating this partial area runoff generation model with the GUH-based runoff routing model is presented; this leads to a generalized GUH. The generalized GUH and the storm response model are then used to estimate physically based flood frequency distributions. and the storm response model are then used to estimate phes catchment had been assumed to be constant for all the storms. In this paper we relax this assumption and allow the initial moisture conditions to vary all the storms. In this paper we relax this assumpen distributions are cast in a scaled dimensionless framework where issues such as catchment scale and similarity can be conveniently addressed. A number of experiments are performed to study the sensitivity of the flood frequency response to some of the "similarity" parameters identified in this formulation. The results indicate that one of the most important components of the derived flood frequency model relates to the specification of processes within the runoff generation model; specifically the inclusion of both saturation excess (Dunne) and Horton infiltration excess runoff production mechanisms. The dominance of these mechanisms over Horton infiltration excess runof prod frequency distribution can significantly affect the distributional shape and confidence limits about the distribution. Comparisons with observed flood distributions shape and confidence limits about the distribution that such mixed runof production mechanisms influence flood distribution shape. The sensitivity analysis also indicated that the incorporation of basin and rainfall storm scale also greatly influences the distributional shape of the flood frequency curve.
\end{abstract}

\section{INTRODUCTION}

Considerable research effort has been spent in recent years on the estimation of flood frequencies using the derived distribution approach. The first example of such an effort was described by Eagleson [1972]. Two more recent examples were presented by Hebson and Wood [1982] and Diaz-Granados et al. [1984]. The rainfall-runoff models used by the latter are based on versions of the geomorphologic unit hydrograph (GUH) proposed by Rodriguez-Iturbe and Valdes [1979].

Despite the simplicity and ease of parameterization of the GUH, a number of significant shortcomings still exist in the use of GUH-based models for the estimation of derived flood frequency. Recently, Moughamian et al. [1987] compared the approaches of Hebson and Wood [1982] and DiazGranados et al. [1984]. They found that both models performed poorly in every catchment studied when compared to sample distributions, suggesting that fundamental improve-

\footnotetext{
'Now at Centre for Water Research, University of Western Australia, Nedlands, Australia.

Copyright 1990 by the American Geophysical Union.

Paper number 89WR01579.

0043-1397/90/89WR-01579\$05.00
}

ments are needed before they can be applied with any confidence.

The GUH of Rodriguez-lturbe and Valdes [1979] is based on the assumption that rainfall excess is generated uniformly throughout the catchment area. In their application of the GUH to derived flood frequency estimation, both Hebson and Wood [1982] and Diaz-Granados et al. [1984] assumed two simple models of essentially Hortonian runoff generation to calculate the rainfall excess. In reality, runoff generation on catchments is much more complex. It is now recognized [Dunne, 1978] that in many catchments much of the runoff during storm events is produced on variable contributing areas which form narrow bands adjacent to the streams. The failure to incorporate these observed features of the catchment response into the GUH-based models is likely to be a source of major errors in the derived flood frequency estimates.

In all of the examples cited above, the initial moisture condition of the catchment prior to the storm is assumed to be the same for all the storms. This is contrary to the reality in many catchments. Wood [1976] extended the flood frequency model of Eagleson [1972] in order to study the effects of parameter uncertainties. He found that uncertainty in the parameter that represented the initial moisture state of the 
catchment could have a substantial effect on the predicted return periods.

In addition, both Hebson and Wood [1982] and DiazGranados et al. [1984] used a lumped representation of the catchment response with spatially homogeneous rainfall based, however, on point rainfall statistics. This inconsistency gives rise to scale-dependent biases in the derived flood frequency distributions. Wood and Hebson [1986] overcame this problem by deriving a scale-independent flood frequency curve using an areal rainfall input distribution based upon areal rainfall similarity.

Finally, Surkan [1969] has shown that catchments that are topologically similar (based for example on Horton's order ratios) may yet produce different impulse response functions. This is the result of topological randomness whereby networks with different link-node configurations give rise to the same order ratios. For this reason, Beven [1986] has argued against generalizing the network for making predictions about specific catchments; instead Beven used a simple routing procedure based on a constant channel wave velocity and network link histogram. More recently, Gupta et al. [1986] have presented an approach that utilizes the actual network structure directly for the routing of runoff through use of the so-called "width function." This is a subject of intense current research interest.

\subsection{Scope of the Paper}

This is the third in a sequence of papers whose aim has been to provide a greater understanding of the interrelationships that underlie the storm response of catchments of different scales and physical characteristics by focusing on concepts of similarity. In the first paper, Woad and Hebson [1986] developed similarity relationships for flood frequency distributions that are independent of basin scale. They obtained a dimensionless flood frequency curve using the GUH basin response model of Rodriguez-lturbe and Valdes [1979] under the assumptions of spatially homogeneous rainfalls and a simple Hortonian runoff generation model consisting of a constant contributing area during the storm events.

Later, Sivapalan et al. [1987] relaxed these assumptions and developed a model of storm runoff generation due to spatially variable rainfalls on heterogeneous catchments taking account of the effects of catchment topography on the within-storm dynamics of runoff contributing areas. This model was also expressed in dimensionless form leading to the identification of five dimensionless catchment similarity parameters and three dimensionless auxiliary variables which govern the scaled storm response.

This paper represents the logical next step toward the development of a physically based flood frequency curve. First, we generalize the existing GUH theory in order to incorporate, in a simple and parsimonious way, runoff generation on partial areas by both the infiltration excess (Hortonian) and saturation excess (Dunne) mechanisms. The generalized GUH is structured in such a way that it can be coupled to the runoff generation model of Sivapalan et al. [1987] by means of the topography-soil index which is used to predict the areal distribution of soil moisture deficits and the proportion of contributing areas. This coupling permits the lumped runoff generation model of Sivapalan et al. [1987] to be integrated with the generalized GUH in a physically consistent manner.
Second, the runoff generation model of Sivapalan et al. [1987] and the generalized GUH are combined together with assumed distributions of rainfall intensity and duration and an assumed distribution of the initial conditions to obtain the flood frequency curve. The scaled dimensionless formulations of Wood and Hebson [1986] and of Sivapalan et al. [1987] are essentially preserved in the derivations of the catchment storm response. The scaled flood frequency distributions are used to address such issues as catchment scale effects and similarity. The sensitivities of the flood frequency curve to changes of various similarity parameters are also investigated.

\subsection{Outline of the Paper}

The paper begins with a summary of the GUH theory. The outline of the theory, given in section 2.1 , is made sufficiently general so as to be able to incorporate partial area runoff generation. This is followed in section 2.2 by the introduction of a runoff generation model based on the topography-soil index. A methodology for combining the partial area runoff generation model with the GUH-based runoff routing model is presented next in sections 2.3 and 2.4; this results in the generalized GUH. The sensitivities of the generalized GUH to two parameters of the partial area generation model are then studied. The results of this study are presented in section 2.5 .

Section 3 involves the estimation of the dimensionless flood frequency distribution. In section 3.1 the dimensionless peak discharge is calculated based on the dimensionless $S$ curve derived from the scaled generalized GUH. Sections 3.2 and 3.3 are devoted to the specification of frequency distributions of the scaled rainfall intensities, storm durations, and the initial conditions. Section 3.4 describes the procedure for the estimation of the flood frequency distribution and return period. Section 4 presents results of the sensitivity analyses carried out on the model with respect to a number of similarity parameters.

\section{Derivation of a Generalized GUH Based on Partial Area Runoff Generation}

\subsection{A Review of the GUH}

Let $T_{B}$ denote the time of travel of any particle of surface runoff from the location of its generation to the catchment outlet. It is assumed that the time-variant instantaneous unit hydrograph (iuh) at the time $\tau, h(t i \tau)$, is given by

$$
H(t \mid \tau)=\frac{d}{d t} P\left(T_{B} \leq t \mid \tau\right)
$$

where $\boldsymbol{P}($ ) denotes the probability of the event given in the parentheses. Note that for all particles that are generated at time $\tau$, both $T_{B}$ and $t$ are measured from the instant $\tau$. The right-hand side of (1) is simply the probability density function (pdf) of $T_{B}$.

Let $\Omega$ be the highest order of the catchment stream network; $c_{i}(1 \leq i \leq \Omega)$ denotes a channel state of order $i$; and $r_{i}(1 \leq i \leq \Omega)$ denotes an overland flow region or hillslope state of order $i$. We assume that runoff is generated only on the hillslopes; rainfall falling directly into stream channels is neglected. We can then define a collection $S=\{s\}$ of paths $s$ 
which a particle of water may follow from the state $r_{i}$ where it is generated to the catchment outlet. Thus we have

$$
P\left(T_{B} \leq t \mid \tau\right)=\sum_{s \in S} P\left(T_{s} \leq t\right) P(s \mid \tau)
$$

where $T_{s}(s \in S)$ is the travel time along a path $s$ and $P(s \mid \tau)$ is the probability of the given path $s$ out of all paths $S$, for given $\tau$. Neglecting the travel time over the hillslopes, any path $s \in S$ necessarily takes a form $s=\left\langle x_{1}, x_{2}, \cdots, x_{k}\right\rangle$, where $x_{1}, x_{2}, \cdots, x_{k} \in\left\{c_{i}, i=1, \Omega\right\}$. For a path $s \in S$ that originates in a hillslope of order $i$ (note that $x_{1}=c_{i}$ ), $P(s \mid \tau)$ is given by

$$
P(s \mid \tau)=\Pi_{i}(\tau) P_{x_{1} x_{2}} P_{x_{2} x_{3}} \cdots P_{x_{k-1} x_{k}}
$$

where $\Pi_{i}(\tau)$ is the probability that the particle of runoff came from a hillslope of order $i$ and $P_{x_{i} x_{j}}$ is the transition probability for the particle between order $x_{i}$ and $x_{j}$. In the general formulation it is equated to the ratio of the number of particles of runoff generated in all the hillslopes of order $i$ to the total number of particles of runoff generated from the entire catchment. The generalized GUH is then obtained by combining (1), (2), and (3). The probabilities $\Pi_{i}(\tau)$, for $i=1$, $\Omega$, in (3) are dependent on the runoff generation model. Their derivation is presented in section 2.3. The assumption neglecting hillslope travel times is reasonable for large catchments or narrow partial areas. The interaction between hillslope and channel travel times over a range of catchment scales is currently being investigated by the authors.

\subsection{Model of Runoff Generation}

The runoff generation model used in this paper is a simplified version of the conceptual model of Sivapalan et al. [1987]. It is based on the fundamental assumption that, under quasi-steady conditions, the difference between the local prestorm water table depth $z_{x}$ at a location $x$ and its catchment-wide average $\bar{z}$ is linearly related to the corresponding difference between $\ln \left(a T_{e} / T_{x} \tan \beta\right)$, a topographysoil index, and its catchment average $\lambda$. This relationship can be expressed as

$$
z_{x}=\bar{z}-\frac{1}{f}\left\{\ln \left(\frac{a T_{e}}{T_{x} \tan \beta}\right)-\lambda\right\}
$$

In (4), $a$ denotes the area draining through location $x$ per unit contour length, $T_{x}$ is a local transmissivity parameter, and $f$ is a hydrogeological constant for the catchment and is a measure of the decline of the saturated hydraulic conductivity with depth. For soils for which this decline is exponential, Beven [1986] showed that $T_{x}=K_{0} / f$, where $K_{0}$ is the saturated conductivity of the surface soil layer; $\lambda$ and $T_{e}$ are given by

$$
\begin{gathered}
\lambda=\frac{1}{A} \int_{A} \ln \left(\frac{a T_{e}}{T_{x} \tan \beta}\right) d A \\
\ln T_{e}=\frac{1}{A} \int_{A} \ln T_{x} d A
\end{gathered}
$$

Given $\bar{z}$ and the spatial pattern of values of the topography-soil index $\ln \left(a T_{e} / T_{x} \tan \beta\right)$, equation (4) enables the prediction of the pattern of local initial water table depths for all points in the catchment.

Generation of saturation excess runoff depends on the initial moisture storage deficit $S_{x}$ at any location $x$. For simplicity, we neglect the downslope redistribution of moisture within the duration of the storm and assume that saturation excess runoff will be generated wherever the cumulative infiltration $M_{g}(\tau)$ exceeds $S_{x}$. It is assumed further that just before the storm the unsaturated zone moisture profile comes close to the case of complete gravity drainage; i.e., reaches "field capacity." This assumption is consistent with field observations. $S_{x}$ may then be uniquely predicted from the depth to the water table. This unique functional relationship between $z_{x}$ and $S_{x}$ is denoted here by $z_{x}=\gamma\left(S_{x}\right)$.

The initial contributing area $A_{c}(0)$ is obtained by using (4) to determine the value of the topography-soil index for which $z_{x} \leq \psi_{c}$, where $\psi_{c}$ is the thickness of the capillary fringe and is assumed to be equal to the air-entry value of the matrix head for the soil. The contributing area is thus given by

$$
\ln \left(\frac{a T_{e}}{T_{x} \tan \beta}\right) \geq \lambda+f \bar{z}-f \psi_{c}
$$

The contributing area $A_{c}$ expands with time during the storm, and at any time $\tau$ after the beginning of the storm, the dynamic contributing area is obtained by determining the locations where $M_{g}(\tau) \geq S_{x}$. In terms of the topography-soil index this condition can be expressed as

$$
\ln \left(\frac{a T_{e}}{T_{x} \tan \beta}\right) \geq \lambda+f \bar{z}-f \gamma\left[M_{g}(\tau)\right]
$$

The model presented by Sivapalan et al. [1987] assumes that infiltration is controlled by the initial moisture content and saturated hydraulic conductivity of the surface layer and neglects the variation of these quantities with depth. This allows analytical solutions for the infiltration process to be developed. Both the rainfall intensity $p$ and the surface hydraulic conductivity $K_{0}$ are assumed to be spatially variable. Rainfall $p$ is assumed to be gamma distributed within the catchment with mean $\bar{p}$ and coefficient of variation $C_{v p} . K_{0}$ is assumed to be lognormally distributed with mean $\bar{K}_{0}$ and coefficient of variation $C_{v K}$. The model uses quasianalytical expressions for mean infiltration rate $m_{g}(\tau)$ and cumulative infiltration volume $M_{g}(\tau)$. These were derived by Sivapalan [1986] based on the Philip [1957] infiltration equation and the time compression approximation.

In this paper, a further simplification of the modeling of infiltration excess runoff is effected by approximating the infiltration process by a single lumped equation that uses the average moisture content over the noncontributing areas. This approximation is justified by the results of Sivapalan et al. [1987] which show that the variation of surface moisture content in space accounts for a negligible component of total runoff.

Following Sivapalan et al. [1987], the model equations are expressed in dimensionless form in terms of five dimensionless similarity parameters and three auxiliary variables. The listing and definition of these eight parameters are presented in Appendix A. For more details, the reader is referred to Sivapalan et al. [1987]. 


\subsection{Derivation of $\mathrm{I}_{i}(\tau)$}

Let $A$ be the area of the entire catchment. We denote by $A_{i}^{*}$ the total area of all the hillslopes that drain directly to streams of order $i ; \theta_{i}$ denotes the proportion of $A_{i}^{*}$ to $A$, i.e., $\theta_{i}=A_{i}^{*} / A$ and $\Sigma \theta_{i}=1$. Expressions for $\theta_{i}$ for a third-order catchment in terms of Horton's order ratios $R_{A}$ and $R_{B}$ are presented in Appendix B.

Let $A_{c}(\tau)$ be the contributing area for the entire catchment defined as the area contributing direct runoff by the saturation excess mechanism. We also define by $A_{c_{i}}^{*}(\tau)$ the total contributing area from all the hillslopes which drain directly to streams of order $i$. Then we can easily establish the following relationship:

$$
\frac{A_{c}(\tau)}{A}=\sum_{i=1}^{\Omega} \theta_{i}\left(\frac{A_{c_{i}}^{*}}{A_{i}^{*}}\right)
$$

Let $m_{\varepsilon}(\tau)$ be the areal mean infiltration rate over the non-contributing area of the catchment, $A-A_{c}(\tau)$. Here $m_{g}(\tau)$ is modeled using an average surface moisture content of the soil over the nonponded area. The areal average rainfall intensity, assumed constant in time during the storm event, is denoted by $\bar{p}$. Then the rate of runoff generation at any time $\tau$ from the entire catchment is given by

$$
q(\tau)=A\left\{\frac{A_{c}(\tau)}{A} \bar{p}+\left(1-\frac{A_{c}(\tau)}{A}\right)\left[p-m_{g}(\tau)\right]\right\}
$$

We also make the scale approximation that the averages of rainfall and the infiltration rate taken over, say, all of the hillslopes that drain directly to streams of order $i$ are equal to the catchment-wide means $\bar{p}$ and $m_{g}(\tau)$, respectively. The mean runoff production rate from all the hillslopes that drain to streams in order $i$ is then given by

$$
q_{i}(\tau)=A_{i}^{*}\left\{\frac{A_{c_{i}}^{*}(\tau)}{A_{i}^{*}} \bar{p}+\left(1-\frac{A_{c_{i}}^{*}(\tau)}{A_{i}^{*}}\right)\left[\bar{p}-m_{g}(\tau)\right]\right\}
$$

The proportion $\Pi_{i}(\tau)$ of the number of particles of runoff generated on all the hillslopes that drain to streams of order $i$, to the total number from the entire catchment is simply $q_{i} / g ;$ thus we have

$$
\begin{aligned}
& \Pi_{i}(\tau)=\frac{A_{i}^{*}}{A}\left\{\frac{A_{c_{i}}^{*}}{A_{i}^{*}} \bar{p}+\left(1-\frac{A_{c_{i}}^{*}}{A_{i}^{*}}\right)\right. \\
&\left.\cdot\left[\bar{p}-m_{g}(\tau)\right]\left[\frac{A_{c}}{A} \bar{p}+\left(1-\frac{A_{c}}{A}\right)\left[\bar{p}-m_{g}(\tau)\right]\right]^{-1}\right\}
\end{aligned}
$$

At this point we approximate $A_{c}^{*} / A_{i}^{*}$ in the infiltration excess component of (10) by the corresponding quantity for the entire catchment $A_{c} / A$. This is a reasonably good approximation when (1) $A_{c}^{*} / A_{i}^{*}$ and $A_{c} / A$ are much less than 1 and (2) surface runoff generation in natural catchments takes place predominantly by the saturation excess mechanism. Based on Freeze's [1974] and Dunne's [1978] reviews of a large number of field studies and computer simulations, it is apparent that these conditions are met in most catchments, especially in humid areas. With this approximation, equation (10) simplifies to

$$
\Pi_{i}(\tau)=\frac{A_{c_{i}}^{*}}{A_{c}} Q_{s}(\tau)+\theta_{i}\left[1-Q_{s}(\tau)\right]
$$

where $Q_{s}(\tau)$ is the proportion of the total runoff rate from the entire catchment that is generated by the saturation excess mechanism and is defined by

$$
Q_{s}(\tau)=\frac{A_{c}}{A} \bar{p}\left[\frac{A_{c}}{A} \bar{p}+\left(1-\frac{A_{c}}{A}\right)\left[\bar{p}-m_{g}(\tau)\right]\right]^{-1}
$$

Note here that the approximate equation (equation (11)) is exact for the two extreme cases, $Q_{s}=0$ (infiltration excess runoff only) and $Q_{s}=1$ (saturation excess only). Also, when $Q_{s}=0, \Pi_{i}(\tau)=\theta_{i}$ which then yields the original GUH of Rodriguez-liurbe and Valdes [1979].

To evaluate $\Pi_{i}(\tau)$, we require expressions for $A_{c}^{*} / A_{c}$. In section 2.4 we derive expressions for $A_{c}^{*} / A_{c}$ in terms of $A_{c} / A$ using geomorphologic principles and the topography-soil index framework of Beven [1986] and Sivapalan et al. [1987].

\subsection{Derivation of $A_{c_{i}}^{*} / A_{c}$}

To disaggregate $A_{c}$ into $A_{c_{i}}^{*}$ for $i=1, \cdots, \Omega$, we assume that the catchment area can be broken up into a number of rectangular plane hillslopes which drain directly to streams of different orders $i$. As outlined in the earlier description of the runoff generation model, the contributing areas are predicted by the topography-soil index $\ln \left(a T_{e} / T_{x} \tan \beta\right)$. Given the threshold value of this index at saturation, In $\left(a T_{e} / T_{x} \tan \beta\right)_{s}$, the proportion of contributing area $A_{c} / A$ can be obtained from the cumulative distribution function of In $\left(a T_{e} / T_{x} \tan \beta\right)$.

The $A_{c} / A$ versus $\ln \left(a T_{e} / T_{x} \tan \beta\right)$ relationship for an idealized rectangular plane hillslope was derived by Beven and Wood [1983]; applying this relationship to the hillslopes that drain directly to streams of order $i$ and whose combined area as defined above is $A_{i}^{*}$, we have

$$
\begin{gathered}
\frac{A_{c_{i}}^{*}}{A_{i}^{*}}=\left\{1-\frac{\bar{s}_{g_{i}}}{\bar{L}_{g}}\left(\frac{T_{x}}{T_{e}}\right)_{s} \exp \left[\ln \left(\frac{a T_{e}}{T_{x} \tan \beta}\right)_{s}\right]\right\} \\
\frac{a}{\tan \beta}<\frac{\bar{L}_{g}}{\bar{s}_{g_{i}}} \\
\frac{A_{c_{i}}^{*}}{A_{i}^{*}}=0 \quad \frac{a}{\tan \beta} \geq \frac{\bar{L}_{g}}{\bar{s}_{g_{i}}}
\end{gathered}
$$

where $\bar{s}_{g_{i}}$ is the mean ground surface slope of the hillslopes in a direction normal to the streams to which they drain and $\bar{L}_{g}$ is the mean length of the hillslopes in the same direction. Horton [1945] and Morisawa [1962] have found that $L_{g}$ in most catchments can be approximated by $1 / 2 D$, where $D$ is the drainage density which does not vary greatly with the order of the catchment and can therefore be assumed to be constant. At very large catchment scales where there is significant nonstationarity in landforms, this assumption would not hold.

We now make use of Horton's [1945] law of stream slopes which can be expressed as

$$
\bar{s}_{i} / \bar{s}_{i-1}=R_{S}
$$

where $\bar{s}_{i}$ is the mean stream slope of ith-order streams. Strahler [1950] observed a consistent relationship between the mean slope of a stream and the mean ground slope of the 
hillslope draining to it. This relationship can be approximated by

$$
\bar{s}_{g_{i}}=c \bar{s}_{i}^{d}
$$

where $c$ and $d$ are constants. Combining (14) and (15), we obtain a "law of hillside slopes" which can be expressed as

$$
\bar{s}_{g} / \bar{s}_{\boldsymbol{B}_{1-1}}=R_{S G} \approx R_{S}^{d}
$$

Substitution of (16) in (13) yields

$$
\begin{aligned}
& \frac{A_{c_{i}}^{*}}{A_{i}^{*}}=\left\{1-\frac{\bar{s}_{z_{1}} R_{s G}^{i-1}}{L_{g}}\left(\frac{T_{x}}{T_{e}}\right)_{s} \exp \left[\ln \left(\frac{a T_{e}}{T_{x} \tan \beta}\right)_{s}\right]\right\} \\
& \frac{a}{\tan \beta}<\frac{L_{g}}{\bar{s}_{g_{1}} R_{S G}^{i-1}} \\
& \frac{A_{c_{i}}^{*}}{A_{i}^{*}}=0 \quad \frac{a}{\tan \beta} \geq \frac{\dot{L}_{g}}{\bar{s}_{g_{1}} R_{S G}^{i-1}}
\end{aligned}
$$

Now,

$$
\frac{A_{c_{1}}^{*}}{A_{c}}=\theta_{i}\left(\frac{A_{c_{i}}^{*}}{A^{*}}\right) /\left(\frac{A_{c}}{A}\right)
$$

Combining (7), (17), and (18) and eliminating ( $a / \tan \beta)$, we can derive expressions for $A_{c}^{*} / A_{c}$ as a function of $A_{c} / A$ and the geomorphologic constants $\theta_{i}$ and $R_{S G}$. The resulting expressions for a third-order catchment are presented in Appendix C.

Both the variables $A_{c} / A$ and $Q_{s}$ are outputs from the conceptual runoff generation model described earlier. Also, $A_{c} / A$ and $Q$, are functions of $\tau$ and are dependent on the rainfall intensity, soil properties, topography, and the initial moisture conditions. The sensitivities of $A_{c} / A$ and $Q_{s}$ to a number of dimensionless similarity parameters and auxiliary variables that represent climatic inputs, catchment properties, and initial conditions were investigated by Sivapalan ef al. [1987].

\subsection{The Generalized GUH}

We define a dimensionless generalized GUH, denoted by $h^{*}\left(t^{*} \mid \tau^{*}\right)$, as

$$
\begin{gathered}
h^{*}\left(t^{*} \mid \tau^{*}\right)=\tau h(t \mid \tau) \\
t^{*}=t / \tau_{l} \quad \tau^{*}=\tau / \tau_{l} \quad t_{r}^{*}=t / \tau_{l}
\end{gathered}
$$

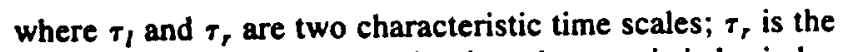
mean duration of storms, and $\tau_{l}$ is a characteristic basin lag time defined here as

$$
\tau_{1}=L_{\boldsymbol{\alpha}} / v
$$

\begin{tabular}{|c|c|c|c|c|}
\hline \multirow[b]{2}{*}{ Parameter } & \multicolumn{4}{|c|}{ Catchment } \\
\hline & $\begin{array}{l}\text { Santa } \\
\text { Paula } \\
\text { Creek }\end{array}$ & $\begin{array}{c}\text { Davidson } \\
\text { River }\end{array}$ & $\begin{array}{l}\text { North } \\
\text { Nashua } \\
\text { River }\end{array}$ & $\begin{array}{l}\text { Bald } \\
\text { Eagle } \\
\text { Creek }\end{array}$ \\
\hline $\begin{array}{l}\text { Area ratio } R_{A} \\
\text { Bifurcation ratio } R_{B} \\
\text { Length ratio } R_{L}\end{array}$ & $\begin{array}{l}6.8 \\
4.7 \\
1.9\end{array}$ & $\begin{array}{l}5.8 \\
4.3 \\
2.1\end{array}$ & $\begin{array}{l}5.6 \\
3.9 \\
3.2\end{array}$ & $\begin{array}{l}3.64 \\
3.17 \\
3.18 \\
\end{array}$ \\
\hline
\end{tabular}

where $L_{\Omega}$ is the length of the highest-order stream in the catchment and $v$ is the mean velocity of flow in the stream network. Following Wood and Hebson [1986], we use an empirical relationship for $\tau_{1}$ (in hours) in terms of the catchment area $\boldsymbol{A}$ (in square kilometers) as follows:

$$
\tau_{l}=2.51 A^{0.38}
$$

TABLE I. Horton's Order Ratios for Four Selected Catchments

Taken from Moughamian et al. [1987] and Hebson and Wood [1982].

Following Rodriguez-Iturbe and Valdes [1979], $h^{*}\left(t^{*} \mid \tau^{*}\right)$ for a third-order catchment is then given by

$$
\begin{aligned}
h^{*}\left(t^{*} \mid \tau^{*}\right)=B \exp \left(-R_{L}^{2} t^{*}\right)+ & C \exp \left(-R_{L^{\prime}} t^{*}\right. \\
& +\left(D+E t^{*}\right) \exp \left(-2 t^{*}\right)
\end{aligned}
$$

The coefficients $B, C, D$, and $E$ are functions of the order ratios $R_{A}, R_{B}, R_{L}$, and $R_{S G}$ and the variables $A_{c} / A$ and $Q_{s}$. The functional relationships of $B, C, D, E$ to $A_{c} / A$ and $Q_{s}$ are expressed through the probabilities $\Pi_{i}$. The expressions for $B, C, D$, and $E$ are presented in Appendix D. In the original formulation of Rodriguez-Iturbe and Valdes [1979], $\Pi_{i}$ are equated to $\theta_{i}$.

The generalized dimensionless GUH was determined for four different combinations of the parameters $R_{A}, R_{B}$, and $R_{L}$ and for different values of the variables $A_{c} / A$ and $Q_{s}$. The values of $R_{A}, R_{B}$, and $R_{L}$ were taken from four catchments analyzed by Moughamian et al. [1987] and Hebson and Wood [1982]. These are summarized in Table 1. $R_{S G}$ was arbitrarily assumed to be 0.62 . The variations of $h_{p}^{*}$, the peak of the dimensionless GUH, with variations of $A_{c} / A$ and $Q_{\text {s }}$ are presented in Figures $1 a$ and $1 b$. They show that partial area runoff generation can have a significant impact on the GUH peak and time to peak in many catchments.

\section{Estimation of Dimensionless Flood FrequenCy}

\subsection{Derivation of Dimensionless Peak Discharge}

Henderson [1963] has found that as long as the unit hydrograph peak and the time to peak are preserved, a triangular unit hydrograph is sufficient for the prediction of streamflow response. Wood and Hebson [1986] derived the peak discharge $Q_{p}$ from a catchment due to storm runofi generated at a constant rate $q$ and having duration $t$, by utilizing a triangular IUH having peak $h_{p}$ and time to peak $t_{p}$. The resulting expression for $Q_{p}$ is as follows:

$$
\begin{array}{ll}
Q_{p}=q h_{p} t_{r}\left(1-\frac{h_{p} t_{r}}{4}\right) & h_{p} t_{r} \leq 2 \\
Q_{p}=q & h_{p} t_{r}>2
\end{array}
$$

In the present paper the rate of runoff generation varies in time even though the generated rainstorms were temporally constant. The results of Beven [1986] suggest that the temporal variations in rainfall can influence the shape of the flood frequency curve. This issue will be addressed in the discussions following the results. To capture the effects of the temporal variation in runoff production, the peak dis- 


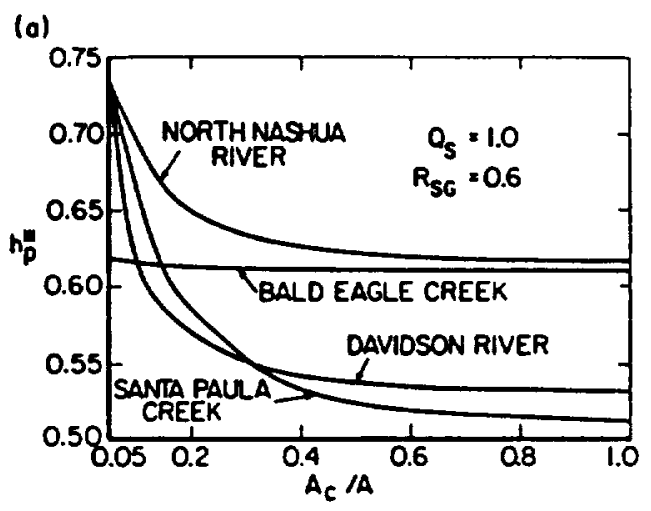

(b)

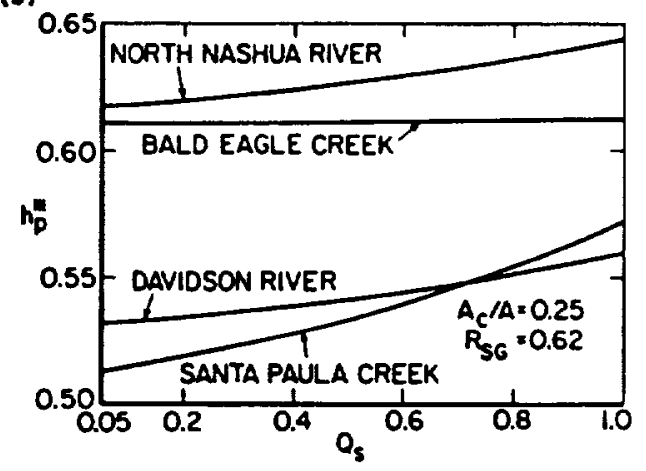

Fig. 1. Variation of $h_{p}^{*}$, the peak of the dimensionless generalized GUH, to (a) $A_{c} / A$ and $(b) Q_{s}$.

charge is calculated using a dimensionless $S^{*}$ curve derived from (22). That is,

$$
\begin{aligned}
S^{*}\left(t^{*}\right)= & \frac{B}{R_{L}^{2}}\left[1.0-\exp \left(-R_{L}^{2} t^{*}\right)\right] \\
& +\frac{C}{R_{L}}\left[1.0-\exp \left(-R_{L^{*}}\right)\right]+0.25(2 D+E) \\
& \cdot\left[1.0-\exp \left(-2 t^{*}\right)\right]-0.5 E t^{*} \exp \left(-2 t^{*}\right)
\end{aligned}
$$

The time-varying runoff production was then convoluted with the dimensionless $S^{*}\left(t^{*}\right)$ curve to yield the outflow hydrograph from which the peak discharge and time to peak were extracted. As discussed in section 2, generalized GUH is a function of $A_{c} / A$ and $Q_{s}$ which are also time variable. For the simulation results presented in this paper, we used time-averaged values, $\bar{A}_{c} / A$ and $\bar{Q}_{s}$, in the calculation of $h^{*}$.

Relationships between the scaled (or dimensionless) and nonscaled discharge values can be established using the time scales $\tau_{l}$ and $\tau_{r}$ defined earlier and the following transformations. These transformations are similar to the ones used by Sivapalan et al. [1987] and are consistent with the definitions presented in Appendix A.

$$
\begin{aligned}
& Q_{p}^{*}=\frac{Q_{p} \tau_{r}}{\psi_{c}\left(\theta_{s}-\theta_{r}\right)} \\
& q^{*}=\frac{q \tau_{r}}{\psi_{c}\left(\theta_{s}-\theta_{r}\right)}
\end{aligned}
$$

The above expressions for the dimensionless peak discharge do not include a base flow component; its treatment is discussed in section 3.3 .

\subsection{Frequency Distributions of Inputs}

As in most previous work, we assume that the scaled storm duration is exponentially distributed; in this case it has mean 1. The scaled point rainfall intensities are assumed to be gamma distributed with parameters $\alpha$ and $\beta$ and coefficient of variation $C_{v}$. Following Wood and Hebson [1986], we assume that the scaled mean rainfall $\bar{p}^{*}$ over a catchment of area $A$ is also gamma distributed with parameters $\alpha_{A}$ and $\beta_{A}$. Wood and Hebson [1986] have shown that

$$
\begin{aligned}
& \alpha_{A}=\alpha \kappa^{-2} \\
& \beta_{A}=\beta \kappa^{2}
\end{aligned}
$$

where $\kappa^{2}$ is a geoclimatic scaling parameter defined by

$$
\sigma_{A}^{2}=\sigma^{2} \kappa^{2}
$$

where $\sigma^{2}$ and $\sigma_{A}^{2}$ are the variances of point rainfall and areal average rainfall, respectively. The $\kappa^{2}$ can be estimated for any catchment area $A$ using the space correlation of the rainfall intensity process.

The variance of point rainfall intensities within a catchment is also important and has a significant effect on predictions of the rates of nunoff generation. The model of Sivapalan et al. [1987] requires the coefficient of variation $C_{v p}$ of point rainfall intensities within the catchment. The relationship between $C_{v p}$ and $C_{v}$ for a catchment of area $A$ is given by

$$
\frac{C_{v p}}{C_{v}}=\left(1-\kappa^{2}\right)^{1 / 2}
$$

Following Sivapalan and Wood [1987], the spatial correlation structure of rainfall is assumed to be of the form

$$
\rho_{p}(r)=a_{1} \exp \left(-b_{1}^{2} r^{2}\right)+a_{2} \exp \left(-b_{2}^{2} r^{2}\right)
$$

where $a_{1}, a_{2}, b_{1}$, and $b_{2}$ are constants with $a_{1}+a_{2}=1$. The correlation length is given by

$$
\lambda_{p}=\int_{0}^{\infty} \rho_{p}(r) d r=\frac{a_{1}(\pi)^{1 / 2}}{b_{1}}+\frac{a_{2}(\pi)^{1 / 2}}{b_{2}}
$$

In this paper we assume $a_{1}=0.7, a_{2}=0.3$, and $b_{1} / b_{2}=3.0$. For such a correlation structure the variation of $\kappa^{2}$ and $C_{u p} / C_{v}$ with the scaled catchment area $A^{*}=A / \lambda_{p}^{2}$ is presented in Figure 2.

\subsection{Distribution of the Initial Condition}

In the model of Sivapalan et al. [1987] the initial moisture state of the catchment is uniquely represented by the auxiliary variable $Q^{*}, Q^{*}$ is a dimensionless baseflow parameter which in combination with the topography-soil index parameter $\phi^{*}$ and the hydrogeologic parameter $\psi_{c}^{*}$ determines the initial contributing areas and the soil moisture in the unsaturated zone (note that the baseflow is inversely proportional to $Q^{*}$ ).

In reality, $Q^{*}$ can vary between storms (short term) as well as between seasons (long term). Ideally, the distribution of 


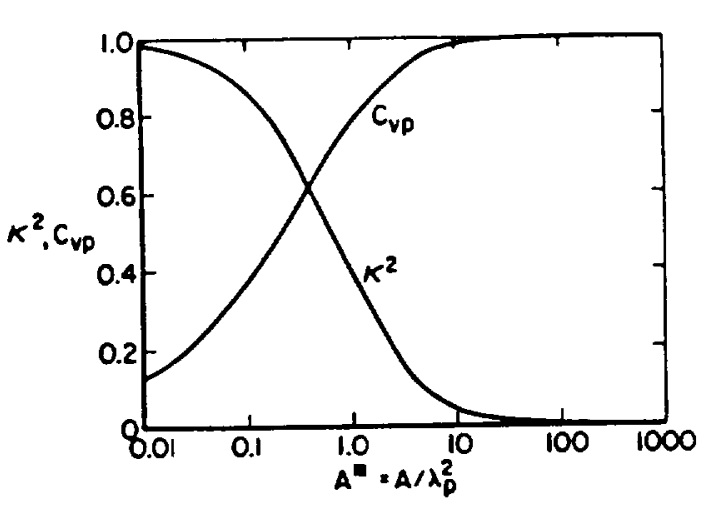

Fig. 2. The variation of $\kappa^{2}$ (the geoclimatic scale parameter) and $C_{u p} / C_{v}$ with scaled catchment area, $A^{*}=A / \lambda_{p}^{2}$.

$Q^{*}$ can only be obtained by the modeling of the processes in the interstorm periods. Although this is the long-term objective of much current hydrologic research, in this paper we arbitrarily assume that $Q^{*}$ belongs to a gamma distribution whose parameters (mean $Q^{*}$ and coefficient of variation $C_{\nu Q}$ ) can be obtained from the analysis of a large number of base flow recession curves of the catchment of interest.

The base flow component of peak discharge can be related to the antecedent moisture conditions which then yields

$$
q{ }_{b}^{*}=\frac{\bar{K}_{0}^{*}}{\left(1+c_{v K}^{2}\right)^{1 / 2} f_{1}} \exp \left(-f_{2} \frac{Q^{*}}{\psi_{c}^{*}}\right)
$$

where $f_{1}=f \exp (\lambda)$ and $f_{2}=f \psi_{c}$. In the present work we have set $f_{1}=400.0$ and $f_{2}=0.40$. Here, $f$ is the parameter that controls the decrease in hydraulic conductivity with depth.

\subsection{Dimensionless Flood Frequency Distribution}

The cumulative distribution function for flood peaks $Q_{p}^{*}$ is given by

$$
F\left(Q_{p}^{*}\right)=\int_{R} f\left(\bar{p}^{*}, t_{r}^{*}, Q^{*}\right) d \bar{p}^{*} d t_{r}^{*} d Q^{*}
$$

where $f\left(\bar{p}^{*}, t_{r}^{*}, Q^{*}\right)$ is the joint probability density function of the point rainfall intensity $\bar{p}^{*}$, rainfall duration, $t_{r}^{*}$, and base flow parameter $Q^{*}$, respectively, and $R$ is the region containing all combinations of $\bar{p}^{*}, t_{r}^{*}$, and $Q^{*}$ for which flood peaks exceed $Q_{p}^{*}$. It is not feasible to analytically evaluate (33) without recourse to further simplifications. For the purposes of this paper, we decided to numerically evaluate the integral in (33) by Monte Carlo simulation. The variables which are assumed to vary from storm to storm are the scaled mean storm intensity $\bar{p}^{*}$, scaled storm duration $t_{r}^{*}$, and the scaled initial soil dryness represented by $Q^{*}$. As discussed below, the distributional characteristics of these variables are assumed fixed for each analysis, thus representing a stable and stationary climate. Nevertheless, due to the nonlinearities in the storm response, both in the transformation from rainfall to runoff generation and in the relationship between fiood peak and basin lag, the derived flood frequency distributions are not scale-independent. The catchment area influences basin lag $\tau$, and geoclimatic scaling parameter $\kappa^{2}$, both of which are important parameters of the flood response.

Realizations of the random variates are then input into the storm response model which results in the output $Q_{p}^{*}$. When arranged in ascending order, this yields the sample cumulative distribution of flood peaks $\hat{F}\left(q_{p}^{*}\right)$. For $n$ storm events per year the annual exceedance series fiood frequency return periods are obtained from

$$
T_{E}\left(Q_{p}^{*}\right)=1 / n \hat{F}\left(Q_{p}^{*}\right) \quad Q_{p}^{*} \geq \hat{F}^{-1}(1 / n)
$$

In the simulations carried out in this work was have used $n=20$ storms per year and simulated a total of 4000 storms; this set was repeated 25 times for a total of $4000(25)$ storm analyses. For many climates, 20 storms per year may be too small. For the object of exploring the effect of catchment characterizations on the shape of the flood frequency curve, 20 is probably sufficient. In section 4 of this paper, further comments are provided on how the results from this analysis can provide insights into the flood frequency characterization in actual catchments.

\section{Results AND Discussion}

A number of experiments were performed with the model to study the sensitivity of the flood frequency response to many of the dimensionless similarity parameters. Some of these parameters (namely, $\bar{p}^{*}, \bar{K}_{0}^{*}, \psi_{c}^{*}, Q^{*}$, and $\phi^{*}$; see Appendix $A$ for their definitions) arose from the runoff generation model and were identified by Sivapalan et al. [1987]. The remainder, $A^{*}, \omega_{T}^{*}, C_{\nu Q}$, and the Horton order ratios $\left(R_{A}, R_{B}, R_{L}\right.$, and $\left.R_{S G}\right)$, were introduced in this paper during the development of the flood frequency model. The parameters were varied, one at a time, from the following arbitrary base values: $\bar{p}^{*}=0.657, \bar{K}_{0}^{*}=0.657, \psi_{c}^{*}=0.05, \bar{Q}^{*}$

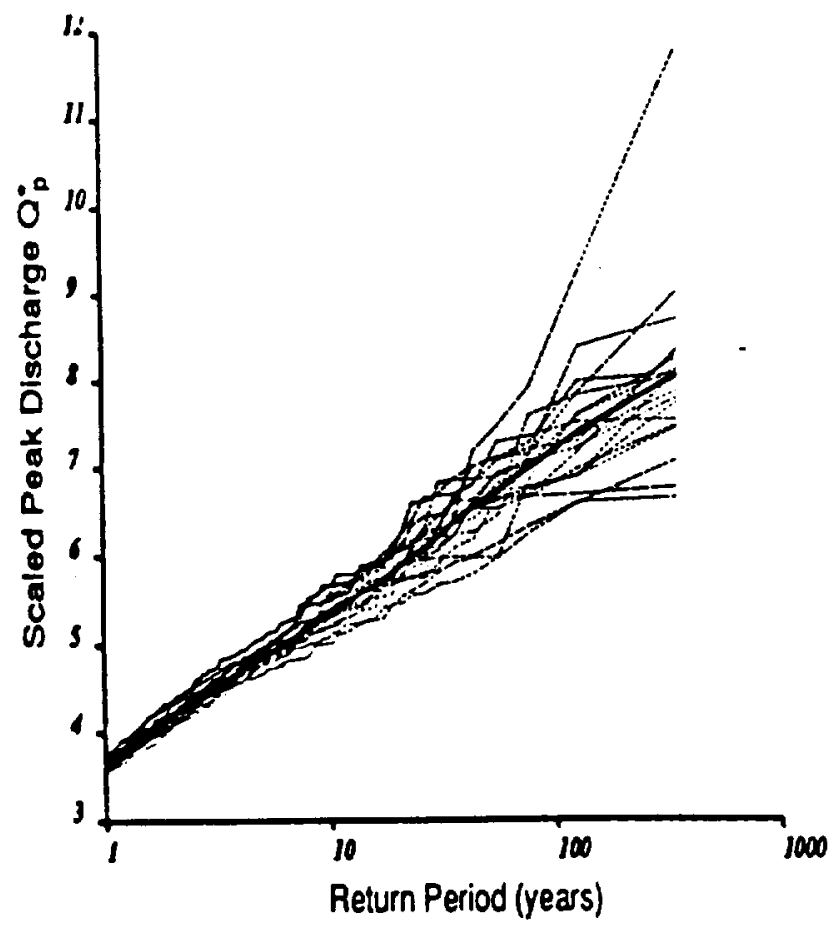

Fig. 3. Variability of the flood frequency distribution over 25 realizations. 

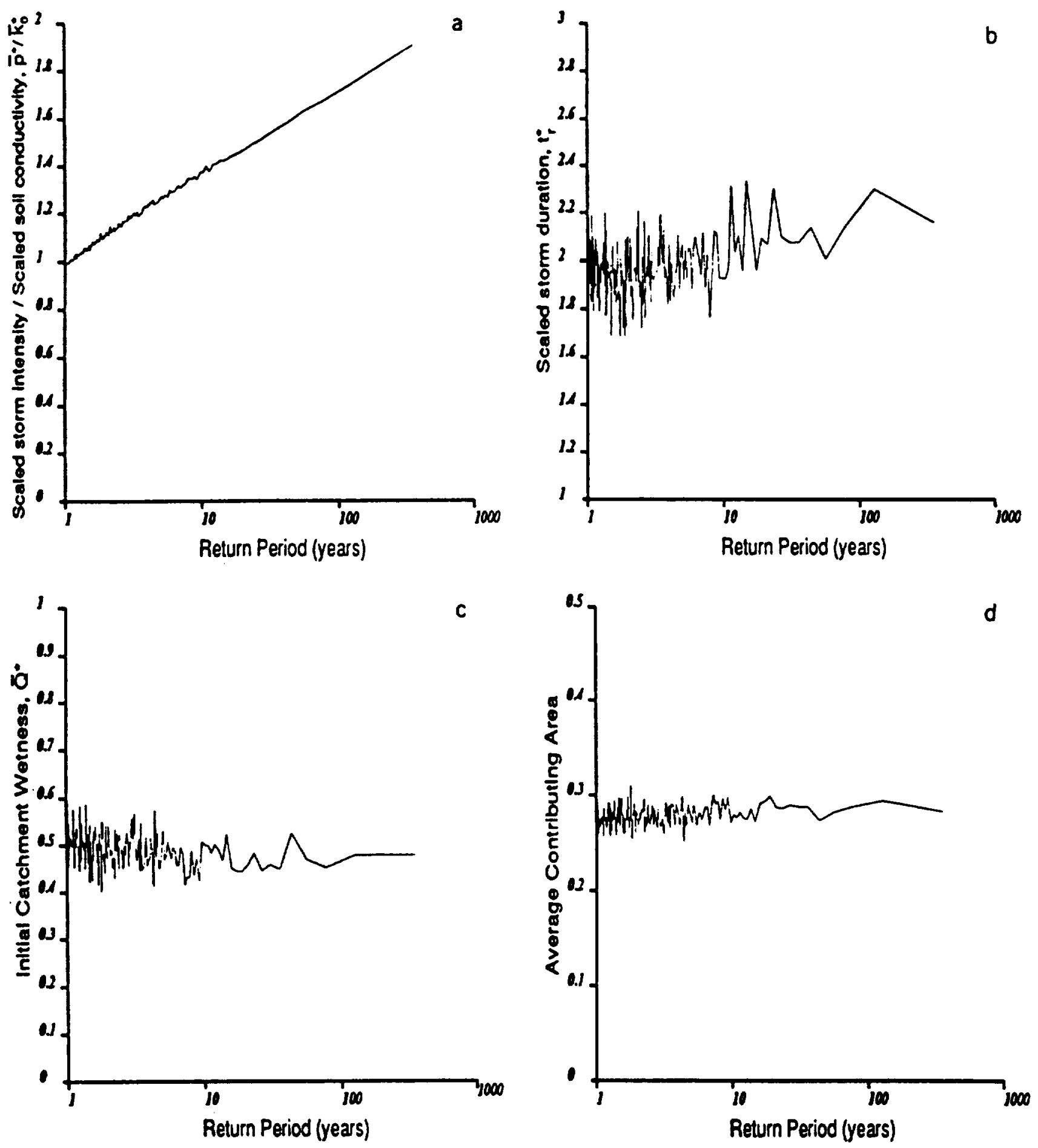

Fig. 4. Value of selected parameters of the runoff generation model corresponding to the flood discharges of Figure 3 , plotted against the discharge return period. The parameters were averaged across the 25 realizations at each return period: (a) scaled storm intensity divided by scaled soil conductivity $\bar{p}^{*} / K_{0}^{*},(b)$ scaled storm duration $t_{r}^{*}$, (c) initial soil wetness $Q^{*},(d)$ average contributing area, and $(e)$ fraction of runoff as saturation excess runoff.

$=0.555, \phi^{*}=2.34, A^{*}=9.0, \omega_{\tau}^{*}=1.45, R_{A}=6.8, R_{B}=$ 4.7, $R_{L}=1.9, R_{S G}=0.62$. The spatial coefficient of variation of the rainstorms, $C_{v}$, was set at a value of 2.0 for all storms; for the soil parameter $K_{0}$, its $C_{\nu K}$, was set equal to 1.0 , and for the initial catchment dryness its $C_{v Q}$ was set equal to 1.0. The Brooks-Corey parameter $B$ was set to 0.40 , $f_{1}=400.0$ and $f_{2}=0.40$ in all simulations. Results using these parameter values will be referred to as the base case.
Figures 3 and 4, presents some results for the base case. In Figure 3 the variability of the derived flood frequency curve for the $\mathbf{2 5}$ repetitions is shown. The average flood frequency curve is darkened and is essentially a straight line showing EV-1 behavior; the same as the rainfall-soil input. This can be seen in Figure $4 a$ where the average frequency curve for $\bar{p}^{*} / \bar{K}_{0}^{*}$ is presented. To construct this, and all remaining figures in the paper, the $2 S$ repetitions were averaged for 


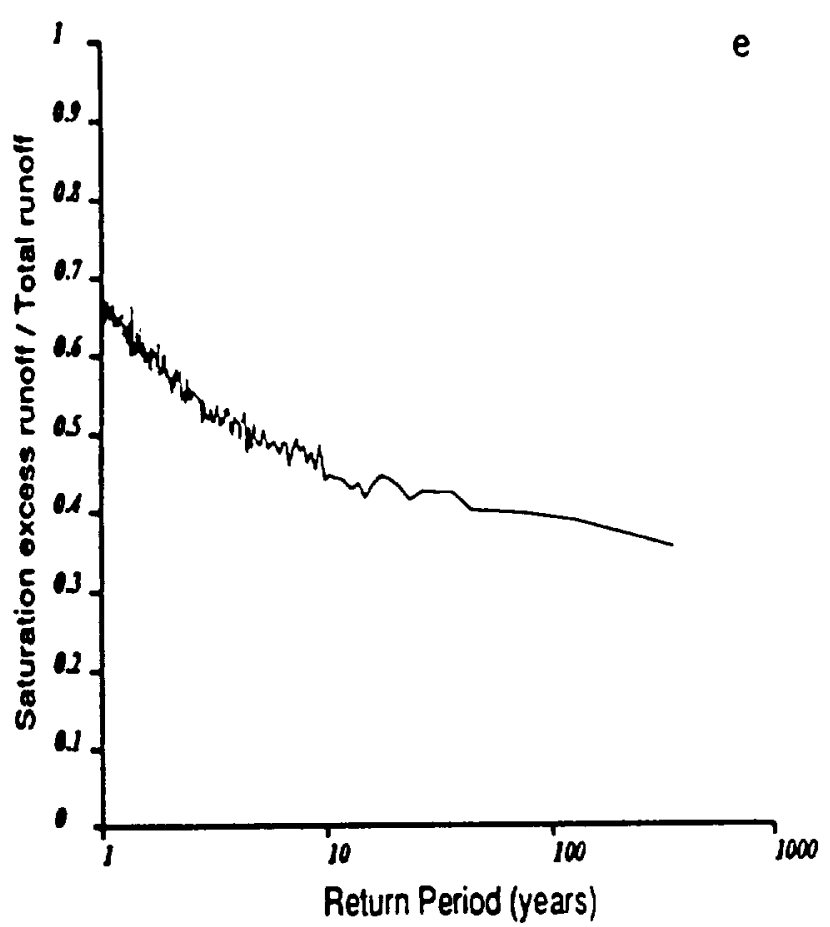

Fig. 4. (continued)

each return period. In Figures $4 b-4 e$ the frequency curves for scaled storm duration $t_{r}^{*}$, initial catchment wetness $Q^{*}$, average contributing area during the storm, and fraction of runoff due to saturated excess runoff mechanism are presented.

These five curves represent the significant hydrologic processes represented in the flood frequency curve. What is

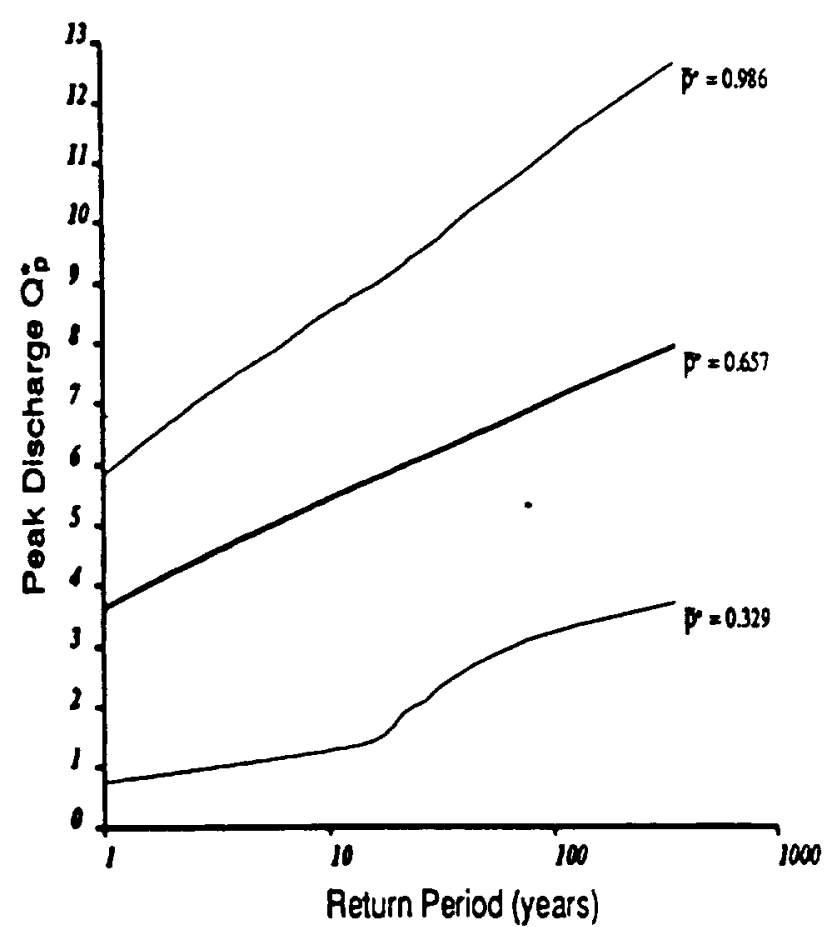

Fig. 5. The sensitivity of the flood frequency distribution to scaled storm intensity $\bar{p}^{*}$. extremely surprising is that it appears that the shape of the flood frequency curve is determined from the shape of the rainfall-soil distribution and that variables such as average contributing area, initial catchment wetness, and storm duration are constant across return periods. Further sensitivity analyses carried out later in this paper show a rather more complex situation than that represented here in the base case. Closer inspection of Figure 4 shows that the floods of importance to the base case catchment are heavily influenced by infiltration excess runoff production (Figure 4e); so perhaps the base case represents a semiarid climate. In this case it is quite reasonable that initial catchment wetness is independent of return period. Somewhat more surprising is to see that on average storm duration is only slightly related to return period and that contributing area is extremely stable at just under $30 \%$. The constant contributing area and increase in infiltration excess runoff with return period demonstrates that for the base case, catchment topography plays only a minor role in the generation of floods of interest.

A series of sensitivity analyses were performed by varying one parameter at a time from the base case. The purpose of these sensitivities is to explore how fundamental hydrologic processes can influence flood frequency characteristics. Curves of the type presented in Figure 4 are available for each parameter set; essentially, only the flood frequency curves (averaged over the 25 repetitions) will be presented for each sensitivity analysis with selected results of other parameters to bring forth important features.

Mean scaled storm intensity. Two additional runs were made to explore increases and decreases of the mean scaled storm intensity. In the base case the mean scaled storm intensity was set equal to the mean scaled soil hydraulic

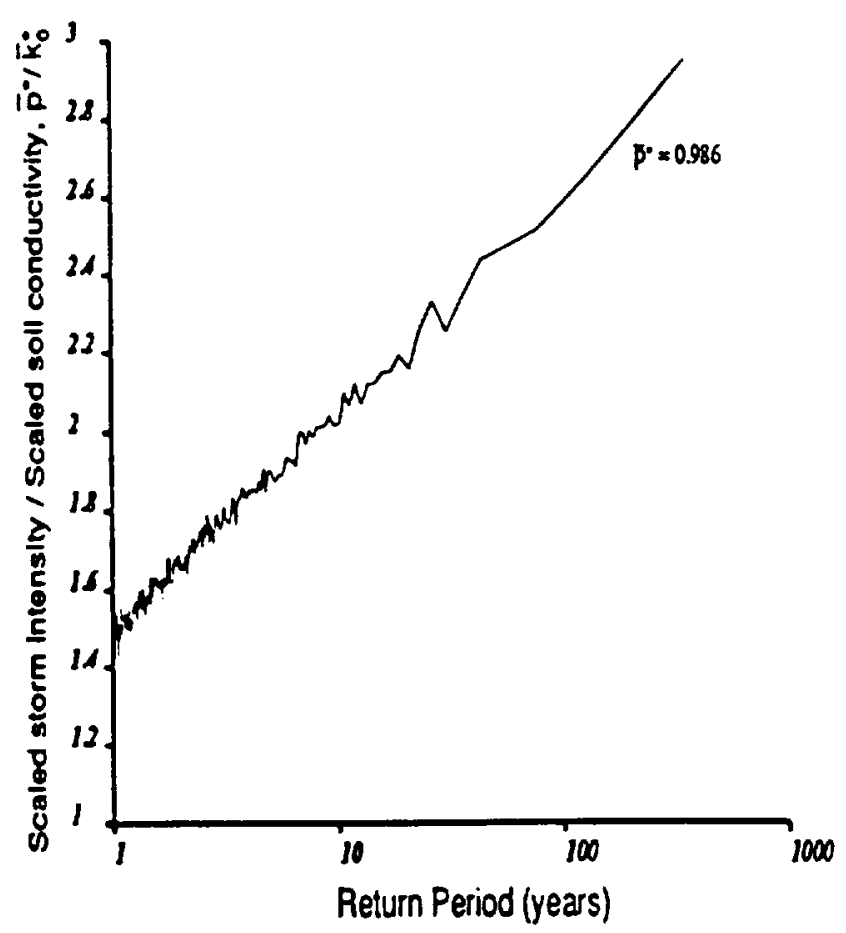

Fig. 6. Values of the scaled storm intensity divided by scaled soil conductivity corresponding to the flood discharges for the sensitivity run of $\tilde{p}^{*}=0.986$, plotted against the discharge return period (averaged over 25 realizations). 

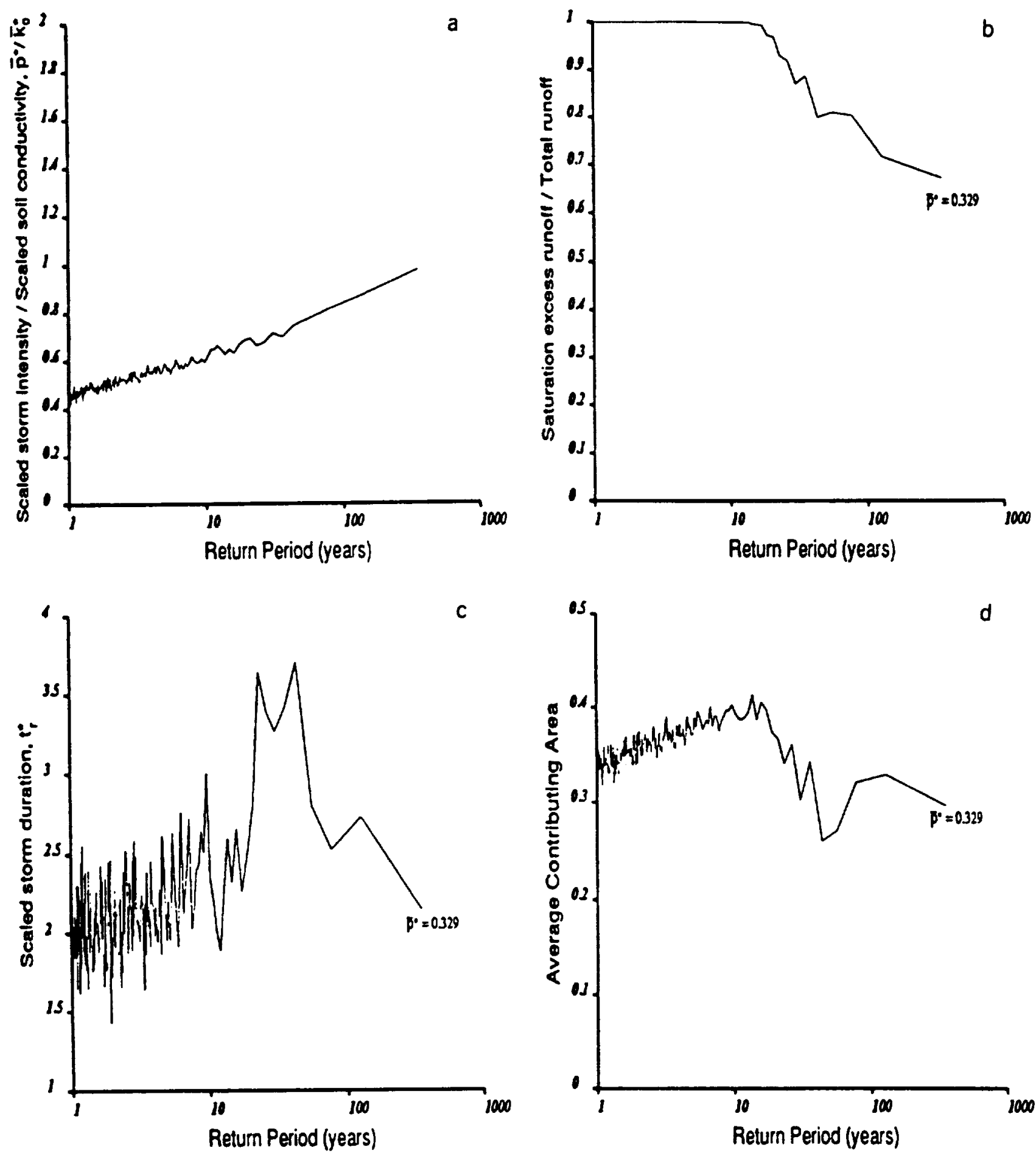

Fig. 7. Value of selected parameters of the runoff generation model corresponding to the flood discharges of the sensitivity run of $\bar{p}^{*}=0.329$, plotted against the discharge return period. The parameters were averaged across the 25 realizations at each return period: $(a)$ scaled storm intensity divided by scaled soil conductivity $\bar{p}^{*} / K_{0}^{*},(b)$ fraction of runoff as saturation excess runoff, $(c)$ scaled storm duration $t_{r,}^{*}(d)$ average contributing area, and $(e)$ initial catchment wetness $\dot{Q}^{*}$.

conductivity. The two additional runs had values $50 \%$ larger and smaller than the base case. Figure 5 shows the results. For the case of $\bar{p}^{*}$ larger than the base case the average flood curve is still linear with the log of the return period but at a steeper slope. This change with respect to the base case is also exactly mimicked in the frequency curve of the rainfallsoil conductivity ratio, as can be seen in Figure 6 . This clearly demonstrates the importance of both soil and rainfall characteristics in determining the basic shape of flood frequency curves. This is even more evident in the analysis of the second sensitivity curve in Figure 5.

The second sensitivity curve had $\bar{p}^{*}$ half of $K_{0}^{*}$ and at first inspection the shape is somewhat confusing in that the curve appears to go towards an EV-3 shape. Upon closer inspec- 


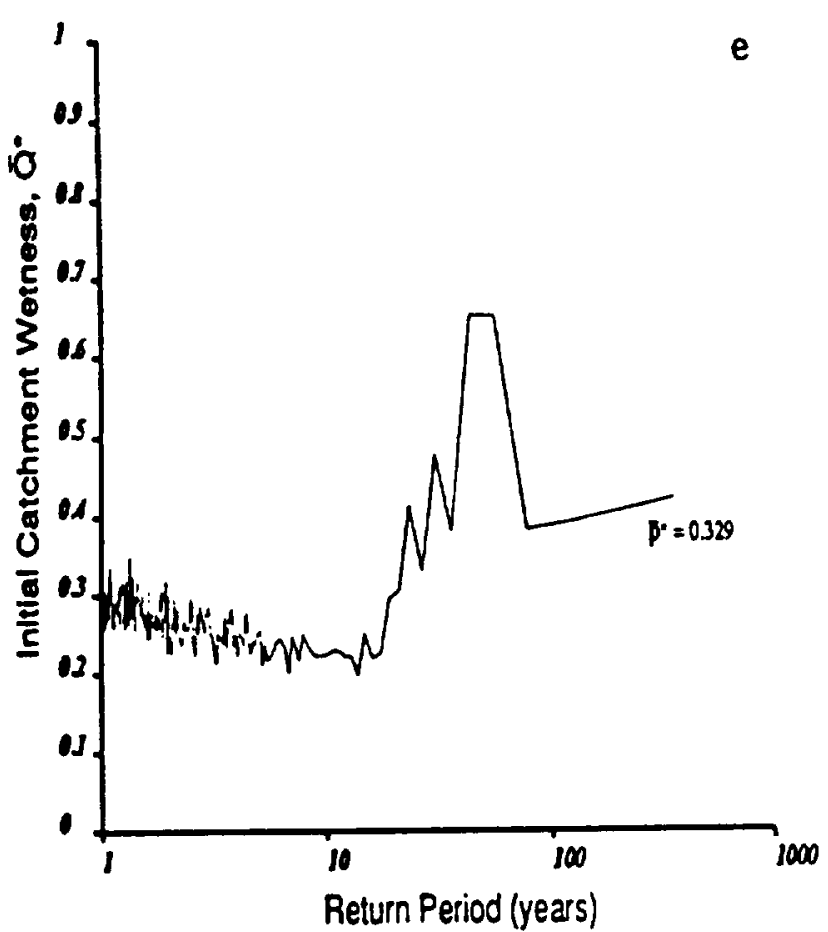

Fig. 7. (continued)

tion, this parameter set provides a catchment where different processes dominate over various parts of the flood frequency curve. For return periods less than about 20 years the flood peaks are completely dominated by saturation excess runoff with a virtual absence of any infiltration excess runoff. At high return periods (greater than 100 years) the flood frequency curve reflects the frequency curve of the rainfall-soil

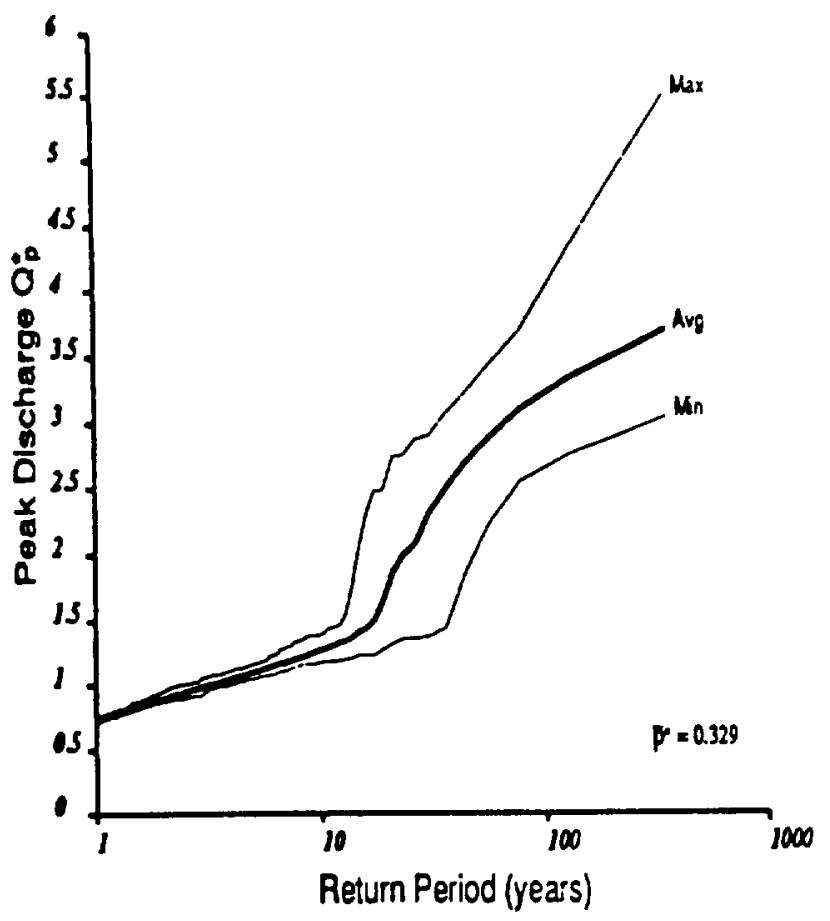

Fig. 8. The envelope, over 25 repetitions, of the flood frequency distribution for the sensitivity run, $\tilde{p}^{*}=0.329$. distribution (as shown in Figure 7a). The shift in the mechanisms can be clearly seen in Figure $7 b$ which shows the fraction of generated runoff due to saturation excess. For low return periods, only saturation excess runoff is generated. For frequencies between 20 and 100 years there is a transition between the two curves. Since the "saturation excess" curve (low return periods) is controlled by catchment topography, there is no real reason why its slope should be the same as the "infiltration excess" flood frequency curve.

Figures $7 c-7 e$ show the frequency curves for scaled storm duration, average contributing area, and initial catchment wetness. From these results it appears that the transition
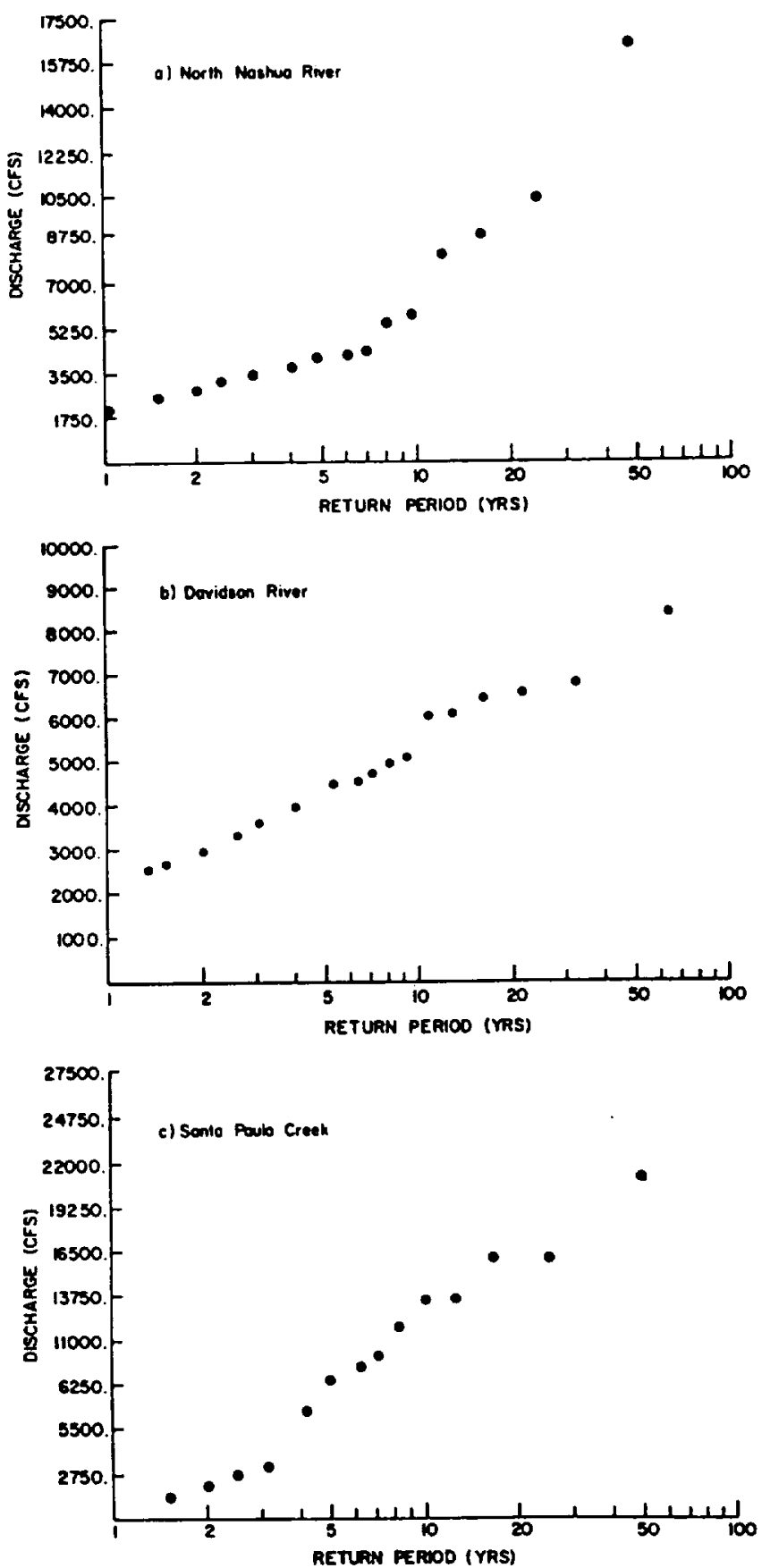

Fig. 9. Flood frequency distributions for three watersheds [after Moughamian et al., [1987]: (a) North Nashua River, (b) Davidson River, and (c) Santa Paula Creek. 


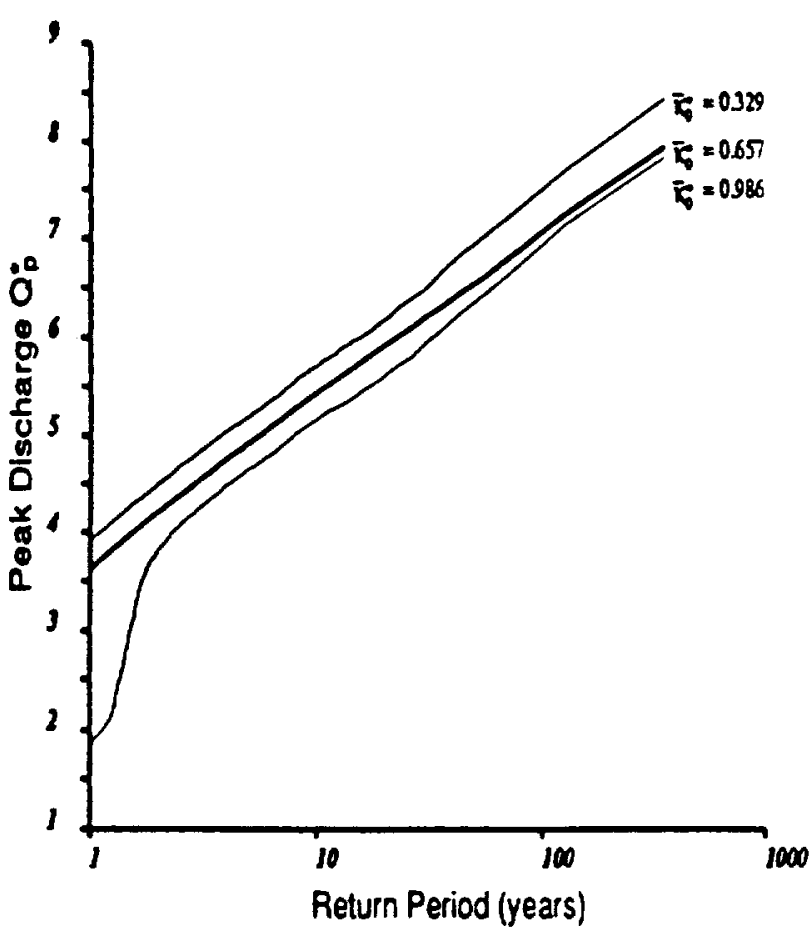

Fig. 10. The sensitivity of the flood frequency distribution to scaled soil conductivity $\bar{K}_{0}^{*}$.

from the saturation excess flood curve to the infiltration excess curve is accompanied by storms that are of long duration on a wet catchment. The uncertainty of the occurrence of this combination in actual catchments contributes to the uncertainty as to when this transition would take place.
Figure 8 shows the envelope for the 25 repetitions using $\bar{p}^{*}=$ 0.329 . The transition appears to start at a scaled peak discharge of about 1.5, with a stable (topographically controlled) saturation excess curve and a somewhat unstable transition and infiltration excess flood curve. The envelope of Figure 8 covers a significant portion of observed flood data and may help explain why fiexible flood frequency curves such as the Wakeby fit data so well.

For actual vegetated catchments, with medium to deep soils having high conductivities (due to forest litter and macropores) when compared to mean storm intensities, such transitions can have an important effect on the flood frequency curve and affect the parameterization of standard flood frequency curves. Figure 9 presents the plotting positions for flood data on three catchments presented by Moughamian et al. [1987]; it is left to the reader to see (imagine?) the transition described here. It should be noted here that the location of the transition can vary as is seen in the sensitivity runs for the mean scaled soil conductivity which are presented next.

Mean scaled soil conducrivity. In a manner similar to the analyses with mean scaled storm intensity, the mean scaled soil hydraulic conductivity was varied $50 \%$ larger and $50 \%$ smaller than the base case. Figure 10 presents the three flood frequency curves (again averaged over 25 repetitions.) The results essentially parallel the results for the storm intensity analysis. Two points should be noticed: similar changes in conductivity produce less sensitivity in the scaled peak flood discharge and the transition from saturation excess to infiltration excess occurred at lower return periods for the parameter sets used. In Figure $7 e$ there was a hint that as the shift to infiltration excess dominated flood curve occurred, the influence of the catchment soil wetness decreased (be-
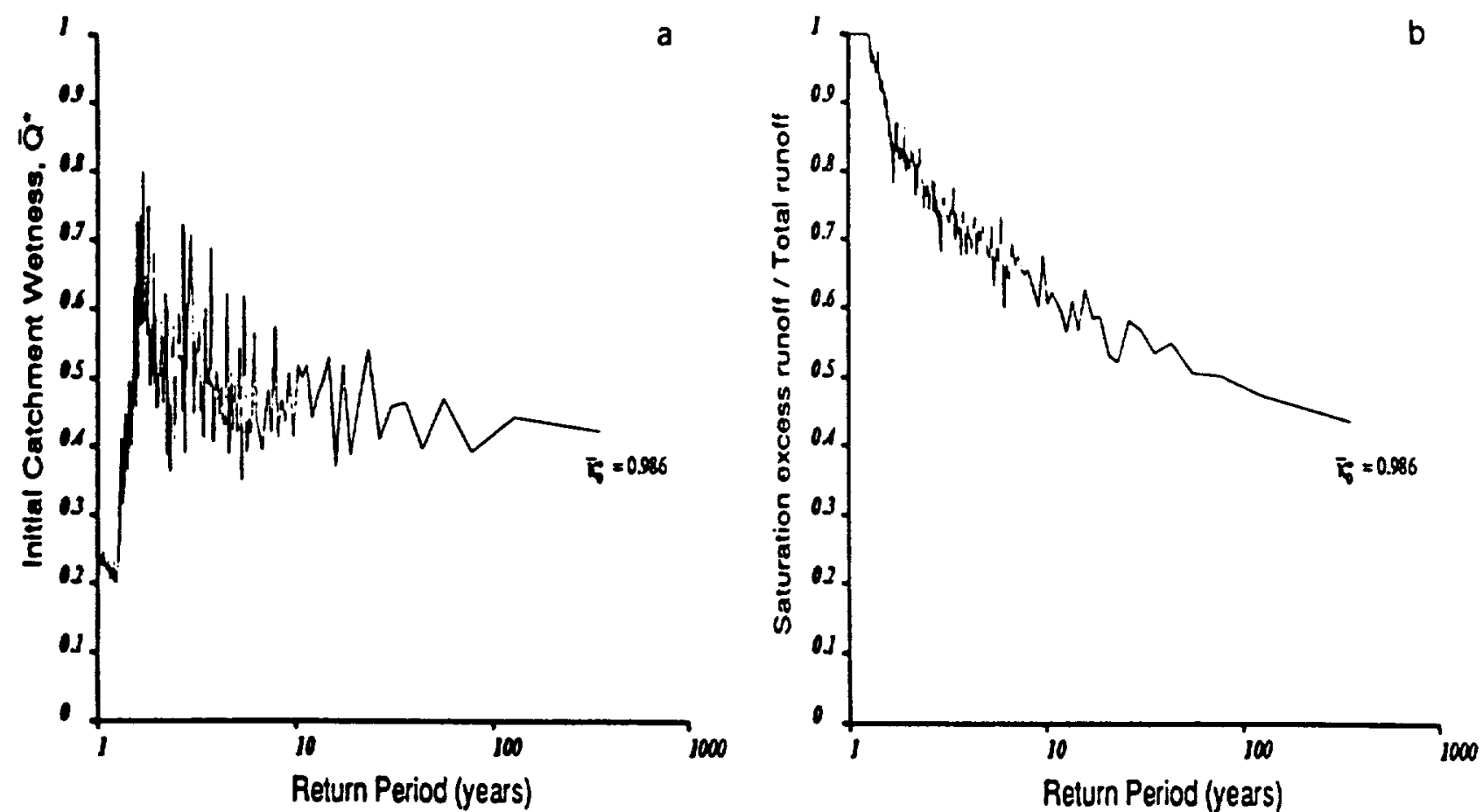

Fig. 11. Value of selected parameters of the runoff generation model corresponding to the flood discharges of the sensitivity run of $K_{0}^{*}=0.986$. plotted against the discharge return period. The parameters were averaged across the 25 realizations at each return period: $(a)$ initial soil wetness $Q^{*}$ and $(b)$ fraction of runoff as saturation excess runoff. 


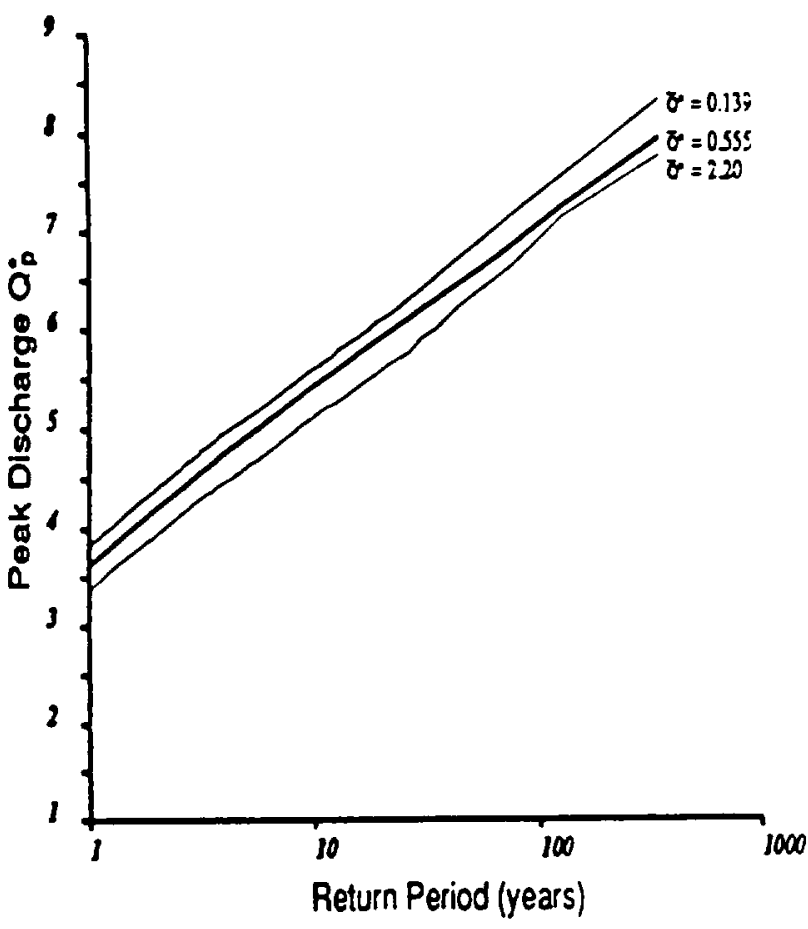

Fig. 12. The sensitivity of the flood frequency distribution to initial soil wetness $Q^{*}$.

came more stable.) Figure $11 a$, which gives the initial catchment wetness for $\bar{K}_{0}^{*}=0.986$, tends to support this. Notice the transition at about the 2- to 5-year return period. Figure $11 b$ gives the fraction of runoff due to the saturation excess mechanism for the same case. Notice that this

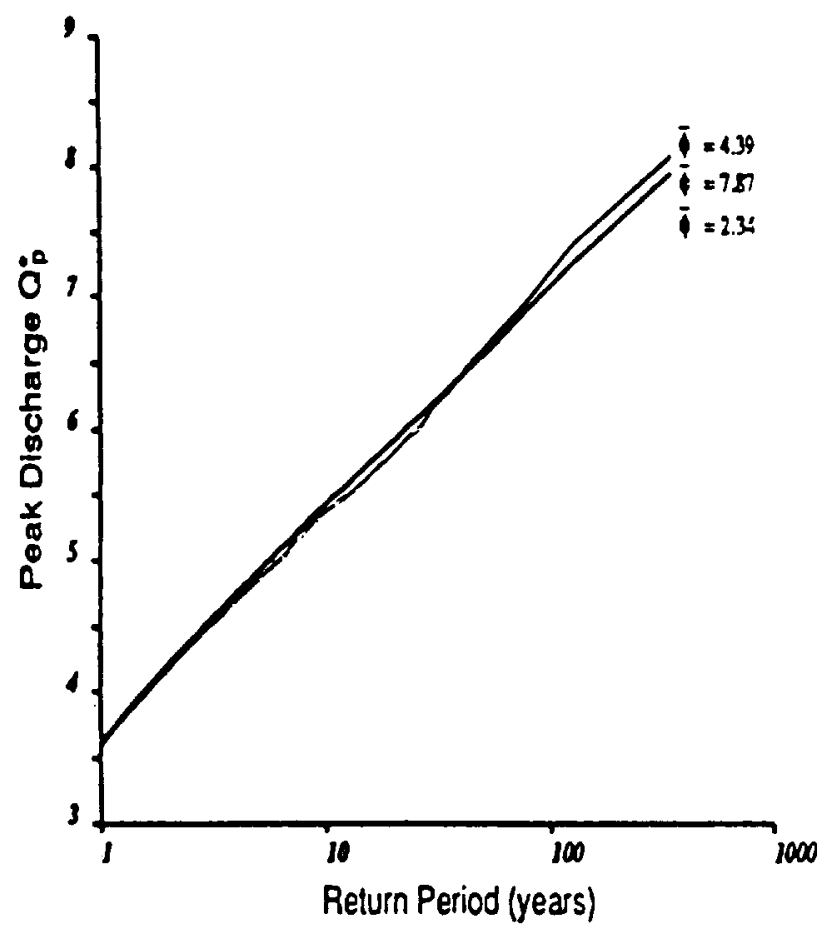

Fig. 13. The sensitivity of the flood frequency distribution to the shape parameter $\phi^{*}$ of the distribution of $\ln \left(a T_{e} / T_{x} \tan \beta\right)$. fraction varies from 1.0 at low return periods to about 0.40 at the 200 year return period.

Initial catchment wettness. The third random input in the Monte Carlo simulations was the initial catchment wetness $\dot{Q}^{*}$. The earlier results showed that for the base case this parameter was stable over all return periods. Therefore one would not expect to see any sensitivity of the flood frequency curve to this parameter. Figure 12 shows this.

Topographic and soil parameters. The flood frequency curve for the base case was infiltration excess dominated. The topographic and soil parameters, $\phi^{*}$ and $\psi_{c}^{*}$ are important in the saturation excess runoff generation. The hydrogeologic parameter $\psi_{c}^{*}$ is a measure of the depth of the soil horizon and thus the depth to the water table. Small $\psi_{c}^{*}$ represents a deep soil horizon and a deep water table. The parameter $\phi^{*}$ is the fitting parameter for the distribution of In $\left(a T_{e} / T_{x} \tan \beta\right)$, the soil-topographic index introduced in section 2.2. Sensitivities from the base case should, therefore, have little influence on the flood frequency curve. Figures 13 and 14 show this. Further work is being done to explore the sensitivity of "saturation excess" dominated catchments to these parameters.

Scaled catchment area. Figure 2 presented the relationship between point rainfall variances within a catchment of area $A$ for a rainfall field having a correlation length $\lambda_{p}$. The ratio $A / \lambda_{D}^{2}$ was defined as $A^{*}$, the scaled catchment area. Large $A^{*}$ correspond to "large" catchments in so much that the catchment is not well covered by a homogeneous rainfall field and the opposite for small values for $A^{*}$. In the base case, $A^{*}$ was set to 9 . Two additional sensitivity runs were performed with $A^{*}$ set to 1 and 36 . Figure 15 presents these results, and it is clear that catchment scale, with respect to the scale of a storm, has a significant impact on the shape of the resulting flood frequency curve. These results support

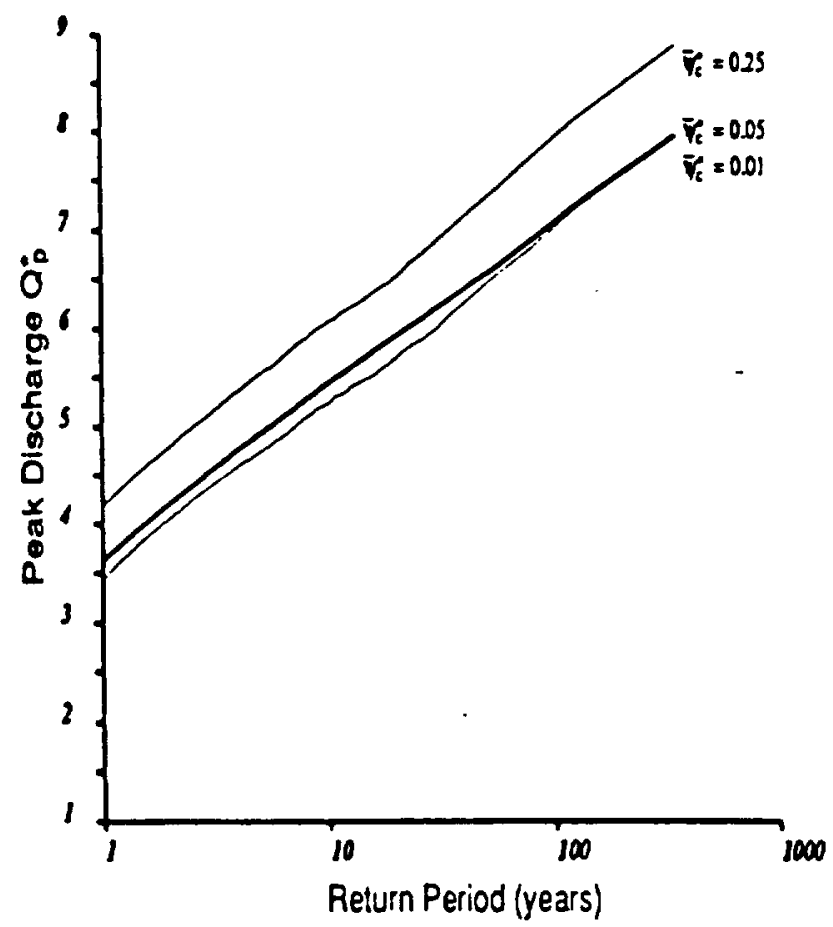

Fig. 14. The sensitivity of the flood frequency distribution to the dimensionless soil parameter $\psi_{c}^{*}$. 
the results presented by Hebson and Wood [1986], which showed that the interplay between catchment and rainfall scales was critical in the shape of the derived flood frequency curve. In actual catchments the value of $A^{*}$ would vary as storms of different types occurred. It is clear from these results that the interplay between scales requires further investigation.

\section{Conclusions}

This paper has described a derived fiood frequency model using a generalized GUH and based on partial area runoff generation. The first objective of the work was to obtain a greater understanding of the interrelationships among processes that underlie the storm response of catchments of different scales and physical characteristics as reflected in flood frequency distributions. We attempted to do this here by casting the storm response model using scaled (or dimensionless) parameters and focusing on concepts of hydrologic similarity. Second, we wished to understand why previous derived flood frequency models based on the GUH have performed poorly and to make significant fundamental improvements to these methods.

In this paper, we adopted a derived flood frequency approach with a GUH-based runoff routing model, following on previous work by Hebson and Wood [1982], DiazGranados et al. [1984], and Wood and Hebson [1986]. Significant improvements were made to these methods through the following extensions: (1) use of a physically based runoff generation model that incorporates runoff generation on partial areas by both infiltration excess and saturation excess mechanisms, (2) use of a generalized GUH based on partial area generation and consistent with extension 1 above, (3) variability of antecedent moisture conditions between storms, and (4) incorporation of the effects of catchment scale both on the rainfall input distributions and in runoff generation.

It has been known for at least 50 years that the important problem in surface hydrology is determining "what to route" not "how to route." Most of the hydrology literature has focused on the latter topic. Our work demonstrates the importance of the former and the mechanism that generated the direct runoff. For example, the results of the Monte Carlo simulations have shown that for catchments dominated by infiltration excess runoff the flood frequency curve is completely defined by the distribution of the scaled rainfall-soil parameter $\bar{p}^{*} / K_{0}^{*}$, and the scaled catchment area $A^{*}$. This emphasizes the need for further research into rainfall distributions, especially the distributions resulting from storms of different types and scales.

For catchments where saturation excess storm production dominates at low flood return periods and infiltration excess dominates at high return periods, the results show that the resulting flood frequency distribution may appear toward an extreme value type 3 (EV-3) curve, implying a limiting flood. Such an interpretation is incorrect, and the flood frequency curve is transitioning to an infiltration excess dominated flood curve. Further research is required to understand the rainfall and catchment characteristics that define the extent of the two mechanisms. The results of the simulation imply that the transition part of the flood frequency curve is produced by long storms of medium intensity on initially wet catchments.

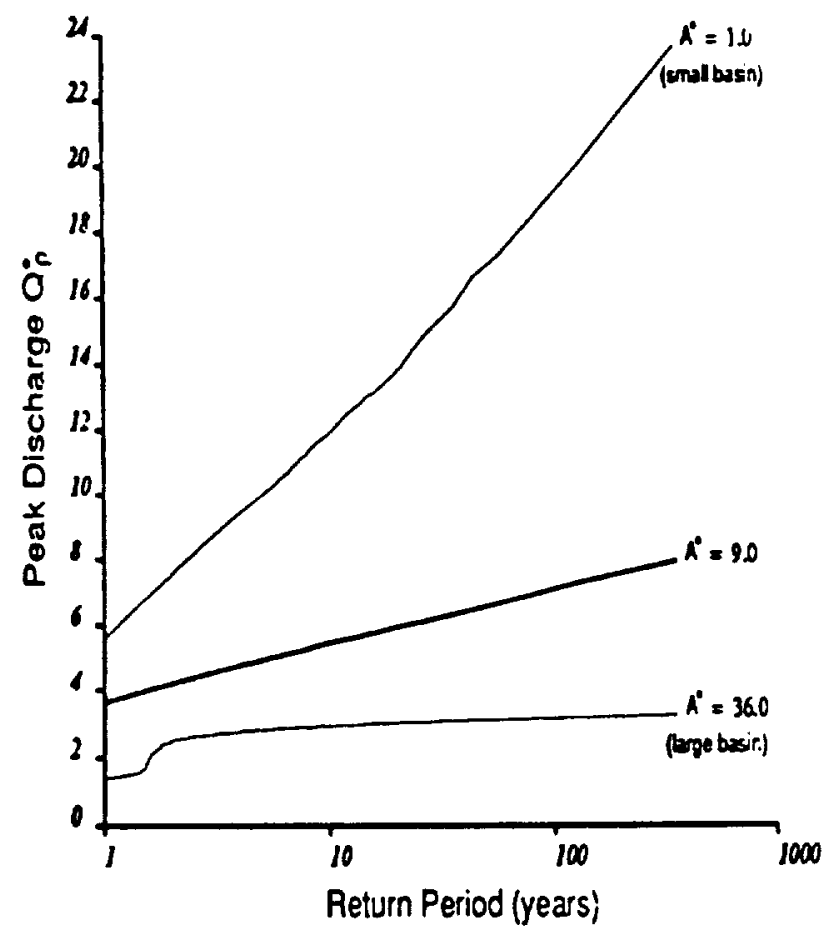

Fig. 15. The sensitivity of the flood frequency distribution to the scaled catchment area $A^{*}$.

The analysis of catchment similarity by means of the kinds of sensitivity analyses carried out in this work have yielded valuable insights into the interrelationships between various processes at the catchment scale. These can help in the development of simple physically based models of catchment behavior. The work in this paper can be extended in a number of directions. The first extension would be to augment the rainfall model to include temporal variability as well as the spatial variability that was considered. Further, the Monte Carlo simulations should randomize storm scale (through $A^{*}$ ) and correlate storm scale with storm characteristics to consider cyclonic and convective storms. The second extension is to expand the range of the Monte Carlo simulations by starting the base case where the mixed mechanisms occurred (Figure 8). This would allow one to explore the sensitivities with respect to those soil and catchment parameters which were not interesting for the base case presented here (e.g., Figures 12-14).

Finally, the flood frequency model developed in this paper needs to be applied to some actual catchments before one can be sure that the conclusions made in this paper correctly explain the flood data presented in Figure 9.

\section{APPENDIX A}

Topography. It is assumed that $\ln \left(a T_{e} / T_{x} \tan \beta\right)$ follows a three-parameter gamma distribution with location parameter $\mu$, scale parameter $\chi^{*}$, and shape parameter $\phi^{*}$ and having mean $\lambda=\mu+\phi^{*} \chi^{*}$.

Soil. The soil hydraulic properties are expressed in terms of the Brooks-Corey relationship with parameter $\theta_{r}$, $\theta_{s}, \psi_{c}$, and $B$ [see Sivapalan et al., [1987].

Hydrogeology. $Q(0)$ is the base flow from the catchment at the beginning of the storm and $Q_{0}$ and $f$ are catchment hydrogeologic parameters and can be estimated by the 
analysis of the baseflow recession curve just prior to the storm.

The following dimensionless parameters can then be defined:

$$
\begin{gathered}
\bar{p}^{*}=\frac{\bar{p}_{r}}{\psi_{c}\left(\theta_{s}-\theta_{r}\right)} \\
\bar{K}_{\sigma}^{*}=\frac{\bar{K}_{0} \tau_{r}}{\psi_{c}\left(\theta_{s}-\theta_{r}\right)} \\
\psi_{c}^{*}=\frac{\psi_{c} f}{\lambda-\mu} \\
Q^{*}=-\frac{\ln \left[Q(0) / Q_{0}\right]}{\lambda-\mu} \\
\phi^{*}
\end{gathered}
$$

$C_{v p}, C_{v K}$, and $B$ complete the list of dimensionless similarity parameters.

\section{APPENDIX B}

The variables $\theta_{i}$ denote the proportion of the hillslopes that drain directly into streams of order $i$. The expressions for $\theta_{i}$ in terms of Horton order ratios are

$$
\begin{gathered}
\theta_{1}=R_{B}^{2} / R_{A}^{2} \\
\theta_{2}=\frac{R_{B}}{R_{A}}-\frac{R_{B}\left(R_{B}^{2}+2 R_{B}-2\right)}{R_{A}^{2}\left(2 R_{B}-1\right)} \\
\theta_{3}=1-\frac{R_{B}}{R_{A}}-\frac{R_{B}\left(R_{B}^{2}-3 R_{B}+2\right)}{R_{A}^{2}\left(2 R_{B}-1\right)}
\end{gathered}
$$

\section{APPENDIX C}

For the following $A_{c} / A$ condition

$$
\frac{A_{c}}{A} \leq \theta_{2}+\theta_{3}-\frac{1}{R_{S G}} \sum_{i=2}^{3} \theta_{i} R_{S G}^{i-1}
$$

The ratios of contributing area for different orders are

$$
\frac{A_{c_{1}}^{*}}{A_{c}}=\frac{A_{c_{2}}^{*}}{A_{c}}=0 \quad \frac{A_{c_{3}}^{*}}{A_{c}}=1
$$

For the following $A_{c} / A$ condition

$\theta_{2}+\theta_{3}-\frac{1}{R_{S G}} \sum_{i=2}^{3} \theta_{i} R_{S G}^{i-1} \leq \frac{A_{c}}{A} \leq 1-\sum_{i=1}^{3} \theta_{i} R_{S G}^{i-1}$

The ratios of contributing area for different orders are

$$
\frac{A_{c_{1}}^{*}}{A_{c}}=0 \quad \frac{A_{c_{1}}^{*}}{A_{c}}=\frac{\theta_{i}}{\left(A_{c} / A\right)}\left\{1-\frac{R_{S G}^{j-1}\left(\theta_{2}+\theta_{3}-A_{c} / A\right.}{\sum_{i=2}^{3} \theta_{i} R_{S G}^{i-1}}\right\}
$$

For the following $A_{c} / A$ condition

$$
\frac{A_{\mathrm{C}}}{A} \geq 1-\sum_{i=1}^{3} \theta_{i} R_{S G}^{i-1}
$$

The ratios of contributing area for different orders are

$$
\frac{A_{c_{i}}^{*}}{A_{c}}=\frac{\theta_{i}}{\left(A_{c} / A\right)}\left\{1-\frac{R_{S G}^{i-1}\left(1-A_{c} / A\right)}{\sum_{i=1}^{3} \theta_{i} R_{S G}^{i-1}}\right\} \quad i=1,2,3
$$

\section{APPENDIX D}

The relationships between the parameters for the third order generalized GUH (equation (22)) and $\Pi_{i}$, the number of particles of runoff generated on all hillslopes draining into streams of order $i$ are as follows:

$$
\begin{gathered}
B=-\Pi_{1} A_{1} R_{L}^{2} \\
C=-\left(\Pi_{1} A_{2}+\Pi_{2} A_{5}\right) R_{L} \\
D=I_{1}\left(A_{3} R_{L}^{2}-2 A_{4}\right)+\Pi_{2}\left(A_{6} R_{L}^{2}-2 A_{7}\right) \\
E=-2\left(\Pi_{1} A_{3}+\Pi_{2} A_{6}+\Pi_{3} A_{8}\right) R_{L}^{2}
\end{gathered}
$$

where

$$
\begin{gathered}
A_{1}=\frac{4\left(P_{13} R_{L}-1\right)}{\left(1-R_{L}\right)\left(2-R_{L}^{2}\right)^{2}} \\
A_{2}=\frac{4 P_{12} R_{L}}{\left(1-R_{L}\right)\left(2-R_{L}\right)^{2}} \\
A_{4}=\frac{2\left(R_{L}^{2}-2 P_{13} R_{L}\right)}{R_{L}\left(2-R_{L}\right)\left(R_{L}^{2}-2\right)} \\
\cdot\left(4 P_{13} R_{L}^{2}\left(2-8 R_{L}^{2}\right)\left(R_{L}-2\right)-\left(12-4 R_{L}-4 R_{L}^{2}+R_{L}^{3}\right)\right] \\
A_{5}=-\frac{4}{\left(2-R_{L}\right)^{2}} \quad A_{6}=\frac{2}{R_{L}\left(2-R_{L}\right)} \\
\left.A_{7}=\frac{R_{L}\left(4-R_{L}\right)}{\left(R_{L}-2\right)^{2}} \quad A_{8}=-2 / R_{L}^{2}\left(R_{L}-2\right)^{2}\right]-1
\end{gathered}
$$

and

$$
\begin{gathered}
P_{12}=\frac{R_{B}^{2}+2 R_{B}-2}{2 R_{B}^{2}-R_{B}} \\
P_{13}=\frac{R_{B}^{2}-3 R_{B}+2}{2 R_{B}^{2}-R_{B}}
\end{gathered}
$$

Acknowledgments. The work presented in this paper was supported in part by NASA Grants NAG-5-491 and NAG-1392, and the U.S. Department of the Interior (USGS) grant 14-08-0001-GI138. This research support is gratefully acknowledged.

\section{REFERENCES}

Beven, K., Runoff production and food frequency in catchments of order $n$ : An alternative approach, in Scale Problems in Hydrol- 
ogy, edited by I. Rodriguez-Iturbe, V. K. Gupta, and E. F. Wood, pp. 107-132, D. Reidel, Hingham, Mass., 1986.

Beven, K., and E. F. Wood, Catchment geomorphology and the dynamics of runoff contributing areas, $J$. Hydrol., 65, $139-158$, 1983.

Diaz-Granados, M. A., J. B. Valdes, and R. L. Bras, A physically based flood frequency distribution, Water Resour. Res., 20(7), 995-1002, 1984.

Dunne, T., Field studies of hillslope flow processes, in Hillslope Hydrology, edited by M. J. Kirkby, pp. 227-294, Chichester, 1978.

Eagleson, P. S., Dynamics of flood frequency, Water Resour. Res., 8(4), 878-898, 1972.

Freeze, R. A., Streamflow generation, Rev. Geophys., 12(4), 627647, 1974.

Gupta, V. K., E. Waymire, and I. Rodriguez-Iturbe, On scales, gravity and network structure in basin nunoff, in Scale Problems in Hydrology, edited by I. Rodriguez-Iturbe, V. K. Gupla, and E. F. Wood, pp. 159-184, D. Reidel, Hingham, Mass., 1986.

Hebson, C., and E. F. Wood, A derived flood frequency distribution using Horton order ratios, Water Resour. Res., 18(5), 1509-1518, 1982.

Hebson, C. S., and E. F. Wood, A study of scale effects in flood frequency response, in Scale Problems in Hydrology, edited by 1. Rodriguez-Iturbe, V. K. Gupta, and E. F. Wood, pp. 133-158, D. Reidel, Hingham, Mass., 1986.

Henderson, F. M., Some properties of the unit hydrograph, $J$. Geophys. Res., 68(16), 4785-4793, 1963.

Horton, R. E., Erosional development of streams and their drainage basins: Hydrophysical approach to quantitative morphology, Geol. Soc. Am. Bull., 56, 275-370, 1945.

Morisawa, M. E., Quantitative geomorphology of some watersheds in the Appalachian Plateau, Geol. Soc. Am. Bull., 73, 1025-1046, 1962.

Moughamian, M. S., D. B. McLaughlin, and R. L. Bras, Estimation of flood frequency: An evaluation of two derived distribution procedures, Water Resour. Res., 23(7), 1309-1319, 1987.
Philip, J. R., Theory of infiltration, 4, Sorptivity and algebraic infiltration equations, Soil Sci., 84, 257-264, 1957.

Rodriguez-Iturbe, I., and J. B. Valdes, The geomorphologic structure of hydrologic response, Water Resour. Res., 15(6), 1409 1420, 1979.

Sivapalan, M., Scale problems in rainfall, infiltration, and runoff production, Ph.D. dissertation, 271 pp., Dep. Civ. Eng., Princeton Univ., Princeton, N. J., 1986.

Sivapalan, M., and E. F. Wood, A multidimensional model of nonstationary space-time rainfall at the catchment scale, Water Resour. Res., 23(7), 1289-1299, 1987.

Sivapalan, M., K. Beven, and E. F. Wood, On hydrologic similarity, 2, A scaled model of storm runoff production, Water Resour. Res., 23(12), 2266-2278, 1987.

Strahler, A. N., Equilibrium theory of erosional slopes approached by frequency distribution analysis, Am. J. Sci., 248, 673-696, $800-814,1950$.

Surkan, A. J., Synthetic hydrographs: Effects of network geometry, Water Resour. Res., 5(1), 112-128, 1969.

Wood, E. F. An analysis of the effects of parameter uncertainty in deterministic hydrologic models, Water Resour. Res., 12(5), 925-932, 1976.

Wood, E. F., and C. S. Hebson, On hydrologic similarity, 1, Derivation of the dimensionless flood frequency curve, Water Resour. Res., 22(11), 1549-1554, 1986.

K. J. Beven, Institute of Environmental and Biological Sciences, University of Lancaster, Bailrigs, Lancaster LAI 4YQ, England.

M. Sivapalan, Centre for Water Research, University of Western Australia, Nedlands, Western Australia 6009, Australia.

E. F. Wood, Water Resources Program, Department of Civil Engineering and Operations Research, Princeton University, Princeton, NJ 08544.

(Received January 28, 1988; revised July 31,1989 ; accepted August 3, 1989.) 

